\title{
Dynamic Wind Effects: A Comparative Study of Provisions in Codes and Standards with Wind Tunnel Data
}

\author{
T. Kijewski ${ }^{1}$, A. Kareem ${ }^{2}$
}

\begin{abstract}
An evaluation and comparison of seven of the world's major building codes and standards is conducted in this study, with specific discussion of their estimations of the alongwind, acrosswind, and torsional response, where applicable, for a given building. The codes and standards highlighted by this study are those of the United States, Japan, Australia, the United Kingdom, Canada, China, and Europe. In addition, the response predicted by using the measured power spectra of the alongwind, acrosswind, and torsional responses for several building shapes tested in a wind tunnel are presented, and a comparison between the response predicted by wind tunnel data and that estimated by some of the standards is conducted. This study serves not only as a comparison of the response estimates by international codes and standards, but also introduces a new set of wind tunnel data for validation of wind tunnel-based empirical expressions.
\end{abstract}

\subsection{Introduction}

Under the influence of dynamic wind loads, typical high-rise buildings oscillate in the alongwind, acrosswind, and torsional directions. The alongwind motion primarily results from pressure fluctuations on the windward and leeward faces, which generally follows the fluctuations in the approach flow, at least in the low frequency range. Therefore, alongwind aerodynamic loads may be quantified analytically utilizing quasi-steady and strip theories, with dynamic effects customarily represented by a random-vibrationbased "Gust Factor Approach" (Davenport 1967, Vellozzi \& Cohen 1968, Vickery 1970, Simiu 1976, Solari 1982, ESDU 1989, Gurley \& Kareem 1993). However, the acrosswind motion is introduced by pressure fluctuations on the side faces which are influenced by fluctuations in the separated shear layers and wake dynamics (Kareem 1982). This renders the applicability of strip and quasi-steady theories rather doubtful. Similarly, the wind-induced torsional effects result from an imbalance in the instantaneous pressure distribution on the building surface. These load effects are further amplified in asymmetric buildings as a result of inertial coupling (Kareem 1985). Due to the complexity of the acrosswind and torsional responses, physical modeling of fluid-structure interactions remains the only viable means of obtaining information on wind loads, though recently, research in the area of computational fluid dynam-

1. Graduate Student \& Corresponding Author, NatHaz Modeling Laboratory, Department of Civil Engineering and Geological Sciences, University of Notre Dame, Notre Dame, IN, 46556. e-mail: Tracy.L.Kijewski.1@nd.edu

2. Professor, NatHaz Modeling Laboratory, Department of Civil Engineering and Geological Sciences, University of Notre Dame, Notre Dame, IN, 46556 
ics is making progress in numerically generating flow fields around bluff bodies exposed to turbulent flows (CWE-92 and CWE 96).

Clearly, a disadvantage to physical modeling is the time, cost, and resources required to conduct a wind tunnel analysis. Furthermore, in the preliminary design stage, a number of building shapes are evaluated and estimates of their response due to wind are calculated, using the resulting response as a criteria to narrow the building shape choices by eliminating those which are aerodynamically unfavorable. Wind tunnel testing of all of these models would not be feasible. Thus, major building codes and standards around the world have begun to develop empirical relationships to produce an estimation procedure to evaluate the acrosswind and torsional dynamic responses in preliminary design, with the understanding that further wind tunnel testing during the final design may be necessary. Thus far, only Japan treats the alongwind, acrosswind, and torsional responses, while Australia and Canada have addressed both the alongwind and acrosswind response in their current standards. On the other hand, the United States and European standards only treat the alongwind direction. Understandably, the development of generalized equations for acrosswind and torsional dynamic responses, based on wind tunnel testing, is a valuable addition to any standard, serving as a cost-effective and time-saving tool in daily design.

It is of interest then, to examine the major international building codes and standards, their treatment of dynamic effects, and how well those estimates compare with measured data. Such comparisons of the suggested procedures given by codes and standards with wind tunnel data, for large collections of actual buildings tested under both isolated conditions and in their actual surroundings, and comparisons with full-scale data have been reported in the literature by Loh \& Isyumov (1985), Ferraro et al (1989), Lee \& $\mathrm{Ng}$ (1988), and AIJ (1996), among others. This study presents an examination of seven major building codes and standards: the Australian Standard: Minimum Design Loads on Structures (known as the SAA Loading Code) (1989), the National Building Code of Canada (1995), the European Prestandard: Eurocode 1: Basis of Design and Actions on Structures (1995), the British Standard: Loadings for Buildings (1995), the ASCE Minimum Design Loads for Buildings and Other Structures (1995), the China National Standard (1987), and the Architectural Institute of Japan (AIJ) Recommendations for Loads on Buildings (1996). A discussion of their treatment of dynamic effects and comparison of their calculated gust factors for a sample building is conducted, concluding with an assessment of their ability to predict the alongwind, acrosswind, and torsional accelerations at the top of a model building, when compared to responses estimated from wind tunnel data. In total, this paper provides a guided tour regarding the usage of the standards and a critical evaluation of the codes' treatment of dynamic effects.

\subsection{Discussion of Existing Standards}

\subsection{General}

Many aspects involved in the estimation of wind loads are held in common by the various codes and standards. Instead of commenting on them repeatedly, they will be highlighted here. First, all the standards break the terrain of any given site down into 3 to 5 categories which will affect the wind characteristics at that location. The design wind speed, associated with one or a range of mean recurrence intervals, used in analysis by each of the codes is typically the product of the basic wind speed and factors to account for the geographic location, topographical effects, and surface roughness, etc. 
Wind gustiness introduces dynamic load effects which the codes and standards account for by factoring up the mean loads by a gust factor. Both time and spatial averaging play an important role in the development of gust factors. For a very small size structure, a short duration gust, which completely engulfs the structure, e.g. a 3-second gust, may be adequate to account for the effects of gustiness, in which case the gust factor is unity. On the other hand, if the wind averaging interval is higher, e.g. 10 minutes or more, the averaged wind exhibits less fluctuations, and accordingly the gust factor is greater than unity. This departure from unity is affected not only by the averaging interval, but also by the site terrain and the size and dynamic characteristics of the structure.

Furthermore, it should also be noted that while all of the standards reference their wind speed at $10 \mathrm{~m}$ above ground in a flat, open exposure, each uses gusts of different duration. The British and Canadian standards use the mean hourly wind speed in design, while the European Prestandard, the China National Standard and the AIJ Recommendations all use a 10 minute mean wind velocity. The ASCE7-95 Standard references a 3 second gust, as does the Australian Standard, though, in the latter case, this wind is later converted to a mean hourly wind for subsequent calculations of dynamic pressure and the gust factor. As a result, for any adequate comparison amongst standards, there must be proper adjustment of the reference velocity.

A gust factor, based on extreme value excursion statistics, representing the most probable or mean extreme wind velocity value or its resulting load effect, is used for determining equivalent static loadings. This approach relies on stochastic dynamics theory to translate the dynamic amplification of loading, caused by turbulence and the dynamic sensitivity of the structure, into an equivalent static loading. The maximum expected wind speed or attendant load effects during an interval $T$ may then be expressed as the summation of the mean value and the RMS value multiplied by a statistically-derived peak factor (Kareem 1987). For example, the expected maximum mean value of a random variable, $X$, related to loading or response is given by:

$$
\begin{gathered}
\bar{X}_{\text {max }}=\bar{X}+g \sigma_{x} \\
G=\frac{\bar{X}_{\text {max }}}{\bar{X}}=1+g \frac{\sigma_{x}}{\bar{X}}
\end{gathered}
$$

where $g$ is the peak factor, $\sigma_{\mathrm{X}}$ is the RMS value of $X$, and $G$ is the gust factor. $\sigma_{\mathrm{X}}$ represents the area under the power spectral density of $X$ which can be described in terms of the background and resonant components. For example, in the case of response, the background component would represent the response due to the quasi-steady effects, while the resonant contribution would denote the response resulting from dynamic amplification, though the relative contribution of each component depends on the dynamic characteristics of the building under consideration. Typically a stiffer building would have major contributions from the background component, whereas for a more flexible structure, the resonant part would dominate.

In the formulation of wind loads, typically the quadratic term introduced by the fluctuating component of wind is ignored. Should this term be retained, it would influence the description of the peak factor which otherwise is derived based on Gaussian assumptions. Detailed treatment of the modeling and contribution of this quadratic term is given in Kareem, et. al (1997). 
In this study, the peak and RMS accelerations estimated by each standard were found using their most detailed dynamic procedure. Thus, while all the standards provide a simplified procedure, only detailed dynamic wind analysis will be discussed herein. Furthermore, an attempt has been made to retain the language and notation presented in each standard when discussing their respective methodologies, since terminology varies internationally.

\subsection{Australian Standard (1989)}

In the Australian Standard (Australian Standard 1989), both an alongwind and acrosswind response may be found following the determination of the design hourly wind speed $\left(\bar{V}_{z}\right)$, as determined by:

$$
\bar{V}_{Z}=V \bar{M}_{(z, c a t)} M_{s} \bar{M}_{t} M_{i}
$$

where $V$ is the basic wind speed pulled from regional maps, $\bar{M}_{(z, c a t)}$ is an hourly mean wind speed multiplier for a terrain category at height, $z, M_{s}$ is a shielding multiplier, $\bar{M}_{t}$ is the topographic multiplier for hourly mean wind speeds, and $M_{i}$ is the structural importance multiplier. The values of each of these terms may be found in appropriate tables in the standard.

The alongwind response of tall buildings and towers is to be determined by the gust factor approach, based upon the fundamental mode of vibration, which has an approximately linear mode shape. The use of the gust factor allows for a quick determination of the peak base overturning moment, found simply by multiplying the mean base overturning moment by the gust factor $(G)$. The gust factor is defined as:

$$
G=1+r \sqrt{g_{v}^{2} B(1+w)^{2}+\left(g_{f}^{2} S E\right) / \zeta}
$$

where:

- $r$ is a roughness factor described by:

$$
r=\frac{2\left(\frac{\sigma_{v}}{\bar{V}}\right)}{\bar{M}_{t}}
$$

with $\left(\frac{\sigma_{v}}{\bar{V}}\right)$, the turbulence intensity, and $\bar{M}_{t}$, the topographic multiplier, provided in tables;

- $g_{v}$ is the peak factor for upwind velocity fluctuation taken as 3.7;

- $B$ is the background factor which measures the slowly varying background component of the fluctuating response caused by the lower frequency wind speed variations, described by: 


$$
B=\frac{1}{1+\frac{\sqrt{36 h^{2}+64 b^{2}}}{L_{h}}}
$$

with $h$ and $b$ being the height and width of the structure, respectively, and $L_{h}$ being the measure of the effective turbulence length, given by $L_{h}=1000\left(\frac{h}{10}\right)^{0.25}$;

- $w$ is a factor to account for the quadratic term in the fluctuating component of the wind, given by:

$$
w=\frac{g_{v} r \sqrt{B}}{4}
$$

- $g_{f}$ is the peak factor, the ratio of the expected peak value which occurs once per hour to the standard deviation of the resonant part of the fluctuating response, given by:

$$
g_{f}=\sqrt{2 \ln \left(3600 n_{a}\right)}
$$

with $n_{a}$ being the fundamental frequency in the alongwind direction;

- $S$ is a size factor to account for the correlation of pressures over a structure, described by:

$$
S=\frac{1}{\left(1+\frac{3.5 n_{a} h}{\overline{V_{h}}}\right)\left(1+\frac{4 n_{a} b}{\overline{V_{h}}}\right)}
$$

and $\overline{V_{h}}$ is the design hourly mean wind speed at the building height, $h$;

- $E$ is a spectrum of turbulence in the approaching wind stream, defined as:

$$
E=\frac{0.47 N}{\left(2+N^{2}\right)^{5 / 6}}
$$

and $N$ is an effective reduced frequency, $\frac{n_{a} L_{h}}{\overline{V_{h}}}$;

- and $\zeta$ is the structural damping capacity as a function of the critical damping ratio, tabularized in lieu of actual estimates.

While the peak and RMS accelerations in the alongwind direction are not specifically given by the standard, they may be found in the commentary by Holmes, et al (1990). In this reference, it is assumed that the peak displacement may be estimated by dividing the peak moment by $M_{I}$ :

$$
\hat{x}=\frac{\hat{M}}{M_{I}}=\frac{\hat{M}}{\frac{1}{3} \rho b d h^{2}\left(2 \pi n_{a}\right)^{2}}
$$


where $\rho$ is the building density, $d$ is the building depth.

The peak moment, $\hat{M}$, is determined by multiplying the mean moment, $\bar{M}$, by the gust factor, $G$. This mean moment is found by summing the moments caused by the forces, $\overline{F z}$, resulting from the mean pressures on the faces of the structure as determined by:

$$
\overline{F z}=\sum C_{p, e} \overline{q_{z}} A_{z}
$$

where $\overline{F z}$ is the hourly mean net horizontal force acting on a building or structure at height, $z, C_{p, e}$ are the pressure coefficients for both windward and leeward surfaces, obtained from tables, $\overline{q_{z}}$ is the free stream hourly mean dynamic wind pressure resulting from the design hourly mean wind speed at height $z, \bar{V}_{z}$, described by $\bar{q}_{z}=0.6\left(\bar{V}_{z}\right)^{2} \times 10^{-3}$; and $A_{z}$ is the area of the structure at height $z$.

The peak alongwind acceleration is then given by:

$$
\hat{a}_{a}=\hat{x}\left(2 \pi n_{a}\right)^{2}
$$

from which the RMS acceleration in the alongwind direction may be found by dividing by the peak factor.

Unlike many of the other codes considered, the Australian Standard also provides some estimation of acrosswind effects, with the peak acceleration $\left(\hat{a_{c}}\right)$ at the top of a building (with nearly constant mass per unit height) given by:

$$
\hat{a}_{c}=\frac{\left(1.5 g_{f} \overline{q_{h}} b\right)}{m_{o}}(0.76+0.24 k) \sqrt{\left(\pi C_{f s}\right) / \zeta}
$$

where terms previously not defined are: $\overline{q_{h}}$, the hourly mean dynamic wind pressure at the building height, $h, k$ is the exponent from representation of the fundamental mode shape as $\psi(z)=\left(\frac{z}{h}\right)^{k}, C_{f_{s}}$ is the acrosswind force spectrum coefficient generalized for a linear mode, and $m_{o}$ is the average mass per unit height of the structure. The acrosswind force spectrum coefficients for buildings with rectangular cross section may be taken from actual spectra plotted as a function of non-dimensional frequency provided in the standard for square shapes (with aspect ratios of 6:1:1 to 9:1:1 and 3:1:1) and rectangular shapes (with aspect ratio of $6: 2: 1$ and $6: 1: 2$ ) for turbulence intensities of 0.12 and 0.20 at 2/3 of the building's height. However, should the building of interest not fall within one of the aspect ratios given above, interpolation between the provided spectra is permitted.

An additional provision is supplied for the combination of alongwind and acrosswind responses, yielding an expression for scalar structural effects such as axial loads in columns, which sums the load effect of the mean response in both the alongwind and acrosswind directions with another term involving the sum of the squares of other related parameters including the gust factor for the alongwind response. 
Commentary: This standard also does an excellent job of explaining what the parameters in each expression represent and their working units. The expressions and tables are easy to follow, making the calculation of the gust factor and the corresponding overturing moments and accelerations not incredibly taxing. Also to the credit of this standard, it does provide a means to estimate the acrosswind response of a structure using cross-wind force spectrum coefficients generalized for a linear mode; however, the force spectrum must be determined from a provided spectra for only a limited number of shapes and aspect ratios. As a result, interpolation must be used if the desired aspect ratio does not correspond to those provided or nearest shape must be selected to approximate the force spectrum coefficient if the desired shape is not available. As wind tunnel tests on several buildings of varying dimension have shown, the spectra can vary greatly, so the interpolation of a given spectra adds some uncertainty to the acrosswind estimate. The acrosswind force spectral amplitude is very sensitive to the level of turbulence in the approach flow and the building aspect ratio, with a summary of wind-tunnel measured data reported in Simiu and Scanlan (1996) highlighting this fact. This sensitivity is particularly important, since various wind tunnel studies, though apparently having similar approach characteristics, differ in details regarding the variation of turbulence along the model height. Finally, the Australian Standard is the only one which includes the contribution of the square of the fluctuating velocity component.

\subsection{Architectural Institute of Japan (AIJ) Recommendations (1996)}

As true of the other standards considered, the AIJ Recommendations (AIJ Recommendations 1996) employs the gust factor approach, which, for the purposes of this study, will be determined by Detailed Procedure II, in which the resonant response generated by the fluctuating wind force is not negligible. Once the mean wind pressure is determined, Detailed Procedure II may then be used to find the gust factor, given various assumptions in the estimation of the alongwind response, including that of a linear fundamental mode, negligible aerodynamic damping, and a power law representation of the mean wind speed and turbulence intensity. The gust factor may then be expressed as:

$$
G_{f}=1+g_{f} r_{f} \sqrt{B_{f}+R_{f}}
$$

where $g_{f}$ is the peak factor is calculated via:

$$
g_{f}=\sqrt{2 \ln v_{f} T}+\frac{0.577}{\sqrt{2 \ln v_{f} T}} \cong \sqrt{2 \ln v_{f} T+1.2}
$$

with $T$ being the observation time, which for a 10 second gust is $600 \mathrm{~s}$, and $v_{f}$ defined as the zero-level crossing rate which is described in the 1993 Recommendations (AIJ Recommendations 1993) as:

$$
v_{f}=n_{o} \sqrt{\frac{R_{f}}{B_{f}+R_{f}}}
$$

in which $n_{o}$ is the natural frequency for the first translational mode in the alongwind direction, and $B_{f}$ and $R_{f}$ are the background excitation and resonance factors, respectively, that, while typically expressed by multiple integrals, have been estimated by approximate expressions: 


$$
\begin{gathered}
B_{f}=1-\frac{1}{\left\{1+5.1\left(L_{H} / \sqrt{H B}\right)^{1.3}(B / H)^{k}\right\}^{1 / 3}}, k=\left\{\begin{array}{c}
0.33, H \geq B \\
-0.33, H<B
\end{array}\right. \\
R_{f}=\frac{\pi}{4 n_{f}} S_{f} F
\end{gathered}
$$

with

$$
S f=\frac{0.84}{\left\{1+2.1\left(n_{o} H / U_{H}\right)\right\}\left\{1+2.1\left(n_{o} B / U_{H}\right)\right\}} \text { and } F=\frac{4\left(n_{o} L_{H} / U_{H}\right)}{\left\{1+71\left(n_{o} L_{H} / U_{H}\right)^{2}\right\}^{5 / 6}}
$$

Here, $L_{H}$ is the turbulence scale, $L_{H}=100\left(\frac{H}{30}\right)^{0.5}, H$ is the building height, $B$ is the building width, $S_{f}$ is the size reduction factor, and $n_{f}$ is the critical damping ratio.

Finally, $r_{f}$ is a factor for the fluctuating wind speed, described by:

$$
r_{f}=\frac{3+3 \alpha}{2+\alpha} I_{H}
$$

where $\alpha$ is the power law exponent for the boundary layer of interest and the turbulence intensity at the building height, $I_{H}$, may be taken as a tabularized value based on terrain category when the structure's height is less than $Z_{b}$, defined in the standard, in that terrain category. For cases where the building height lies somewhere between $Z_{b}$ and the gradient height $\left(Z_{G}\right)$ in that category, the turbulence intensity at the building height is defined by:

$$
I_{H}=0.1\left(H / Z_{G}\right)^{-\alpha-0.05} .
$$

Tamura et al (1996) provides a method to determine the RMS acceleration of the structure:

$$
\sigma_{\ddot{x}}(z)=\left(2 \pi n_{o}\right)^{2} \sigma_{x}(z) \sqrt{\frac{R_{f}}{B_{f}+R_{f}}}
$$

where $\sigma_{\mathrm{x}}$ is the RMS response of the structure, which may be approximated by:

$$
\sigma_{x}=2 \phi(x)\left[\frac{q_{H} C_{D} B H}{K}\right]\left[\frac{1}{1+\alpha+\beta}\left(\frac{Z_{R}}{H}\right)^{\alpha}\right] I_{R} \sqrt{B_{f}+R_{f}}
$$

where:

- $\phi(x)$ is the mode shape; 
- $C_{D}$ is the alongwind force coefficient, found by appropriate techniques;

- $K$ is the modal stiffness;

- $\beta$ is the mode exponent;

- $Z_{R}$, the reference height, is taken as the structure's height;

- and $I_{R}$, the turbulence intensity at the reference height, would thus be the turbulence intensity at the building height.

Peak accelerations are then simply found by multiplying by the appropriate peak factor, taken as:

$$
g_{\ddot{x}}=\sqrt{2 \ln \left(600 n_{o}\right)+1.2}
$$

Since quasi-steady theory fails to predict the acrosswind and torsional responses, they must be instead determined from empirical expressions. The acrosswind vibration and its resulting load are estimated using the data of RMS overturning moments in that direction derived from wind tunnel tests for rectangular buildings of various aspect ratios up to 6. From this, an expression for the acrosswind RMS acceleration was developed:

$$
\sigma_{\ddot{y}}=3 q_{H} C_{L} \frac{B}{m} \frac{z}{H} \sqrt{R_{L}}
$$

where $m$ is the mass per unit height, $z$ is the height at which the RMS acceleration is being calculated, $q_{H}$ is the dynamic wind pressure given by the appropriate formula for the terrain category of interest, $C_{L}{ }_{L}$ is the RMS overturning moment coefficient in the acrosswind direction, given by:

$$
C_{L}{ }^{\prime}=0.0082(D / B)^{3}-0.071(D / B)^{2}+0.22(D / B)
$$

and $R_{L}$ is given by:

$$
R_{L}=\frac{\pi F_{L}}{4 n_{f}}
$$

where $n_{f}$ is the critical damping ratio for the first translational mode. A computation equation is provided for the wind force spectrum factor, $F_{L}$, shown to agree reasonably with those of wind tunnel studies:

$$
\begin{gathered}
F_{L}=\sum_{j=1}^{N} \frac{4 \kappa_{j}\left(1+0.6 \beta_{j}\right) \beta_{j}}{\pi} \frac{\left(n_{o} / n_{s j}\right)^{2}}{\left\{1-\left(n_{o} / n_{s j}\right)^{2}\right\}^{2}+4 \beta_{j}{ }^{2}\left(n_{o} / n_{s j}\right)^{2}} \\
\left\{\begin{array}{l}
\kappa_{1} \approx 0.85 \\
\kappa_{2} \approx 0.02
\end{array}\right.
\end{gathered}
$$


$\beta_{\mathrm{j}}$ relates the band width and $n_{s j}$ represents the peak frequencies (i.e. vortex shedding frequencies). These quantities are described by empirical relationships as functions of the side ratio $D / B$ :

$$
\begin{gathered}
n_{s 1}=\frac{0.12}{\left\{1+0.38(D / B)^{2}\right\}^{0.89}} \frac{U_{H}}{B} \\
n_{s 2}=\frac{0.56}{(D / B)^{0.85}} \frac{U_{H}}{B} \\
\beta_{1}=\frac{(D / B)^{4}}{1.2(D / B)^{4}-1.7(D / B)^{2}+21}+\frac{0.12}{D / B} \\
\beta_{2}=0.28(D / B)^{-0.34}
\end{gathered}
$$

where $U_{H}$ is the velocity at the building height.

Upon comparison with full scale data, AIJ has determined that the values produced by Eq. (26) are within $\pm 30 \%$.

The empirical expression for the torsional response was also based on a set of wind tunnel studies paralleling those mentioned above. In this case, the experimental data was collected on the response angle acceleration, and a non-dimensional expression for this acceleration was introduced which applies only to buildings which have negligible eccentric effects. Following the same assumptions of the acrosswind analysis, a torsional response angle acceleration may be estimated by:

$$
\sigma_{\ddot{\theta}}=\frac{2 \rho C_{T} n_{o}^{2} \sqrt{B D}}{L \rho_{b} \sqrt{n_{f}}} K_{T} U^{*}{ }^{\left(\beta_{T}+2\right)}
$$

where $\rho$ is the air density, $\rho_{\mathrm{b}}$ is the building density, $L$ is the larger of $B$ or $D, n_{o}$ is the natural frequency for the first torsional mode, $n_{f}$ is the critical damping ratio for the first mode, $C_{T}{ }^{\prime}$ is the RMS torsional moment coefficient, given by:

$$
C_{T}^{\prime}=\left\{0.0066+0.015(D / B)^{2}\right\}^{0.76},
$$

$U^{*}$ is a non-dimensional design wind speed at reference height $\left(U_{H} /\left(n_{o} \sqrt{B D}\right)\right)$, and $K_{T}$ and $\beta_{\mathrm{T}}$ are reduced coefficients for response angle acceleration: 


$$
\begin{gathered}
K_{T}=\left\{\begin{array}{c}
\frac{-1.1(D / B)+0.97}{(D / B)^{2}+0.85(D / B)+3.3}+0.17,\left[U^{*} \leq 4.5\right] \\
\frac{(D / B)-0.16}{(D / B)^{2}+0.96(D / B)+0.42}+\frac{0.35}{D / B}-0.095,\left[6 \leq U^{*} \leq 10\right]
\end{array}\right. \\
\beta_{T}=\left\{\begin{array}{c}
\frac{(D / B)+3.6}{(D / B)^{2}+5.1(D / B)+9.1}+\frac{0.14}{D / B}+0.14,\left[U^{*} \leq 4.5\right] \\
\frac{0.44(D / B)^{2}-0.0064}{(D / B)^{4}-0.26(D / B)^{2}+0.1}+0.2,\left[6 \leq U^{*} \leq 10\right]
\end{array}\right.
\end{gathered}
$$

In comparison with full scale data, the values produced by Eq. (34) are shown to typically overestimate the measured angular tip acceleration by $30 \%$.

Commentary: The AIJ recommendations are fashioned more as a "teaching code," providing a detailed description of the procedure alongside the steps themselves. The code does an excellent job of developing the theory behind the expressions presented and defining their range of validity and should be commended on being the only to provide expressions for both the acrosswind and torsional RMS accelerations; however, a methodology for determining the displacements and accelerations for the alongwind direction needs to be more clearly defined in the current standard with all necessary parameters and methodologies, including the determination of the velocity and pressure at the building height for any category. In addition, AIJ should be commended for showing comparisons between the empirical relationships used in the standard and full scale data to confirm their validity.

\subsection{National Building Code of Canada (1995)}

As with the standards discussed previously, the National Building Code of Canada (National Building Code of Canada 1995) defines two separate procedures for the estimation of wind loads on structures - a simplified or detailed procedure. The detailed analysis is an equivalent procedure based on wind tunnel test results and should be used for light-weight buildings or those of extreme height, with low frequencies or suffering from low damping, and proceeds as follows.

Once the reference wind pressure $(q)$ is determined, which provides the static pressure intended to produce the same load effect as the dynamic resonant response to the actual fluctuating component of the wind, the peak alongwind acceleration may be determined by:

$$
a_{D}=g_{p} \sqrt{\frac{K s F}{C_{e} \beta}}\left(\frac{3.9}{2+\alpha}\right)\left(\frac{\left(C_{e} q\right)}{D \rho_{B}}\right)
$$

where

- $K$ is a surface roughness coefficient to account for the terrain roughness;

- $\beta$ is the first mode alongwind critical damping ratio; 
- $\alpha$ is the boundary layer exponent for a particular terrain;

- $D$ is the structure's depth;

- $\rho_{\mathrm{B}}$ is the structure's density;

- $g_{p}$ is the peak factor which may be taken from figures in the code or calculated by:

$$
g_{p}=\sqrt{2 \ln v T}+\frac{0.577}{\sqrt{2 \ln v T}}
$$

with $\mathrm{T}$, the sample time, taken as $3600 \mathrm{~s}$, and $\mathrm{v}$, the average fluctuation rate, given by:

$$
v=n_{o} \sqrt{\frac{s F}{s F+\beta_{D} B}}
$$

where $n_{o}$ is the fundamental natural frequency and $B$ is the background turbulence factor obtained from figures in the code or by:

$$
B=\frac{4}{3} \int_{0}^{914 / H}\left[\frac{1}{1+\frac{x H}{457}}\right]\left[\frac{1}{1+\frac{x W}{122}}\right]\left[\frac{x}{\left(1-x^{2}\right)^{4 / 3}}\right] d x
$$

where $H$ and $W$ are the structure's height and width, respectively.

- $F$ is gust energy ratio at the natural frequency, taken from plots or calculated by:

$$
\begin{gathered}
F=\frac{x_{o}^{2}}{\left(1+x_{o}^{2}\right)^{4 / 3}} \\
\text { and } x_{o}=\left(1220 n_{o} / V_{H}\right)
\end{gathered}
$$

where $V_{H}$ is the mean wind speed at the top of the structure;

- $s$ is size reduction factor which may be taken from plots provided in the code or calculated by:

$$
s=\frac{\pi}{3}\left[\frac{1}{1+\frac{8 n_{o} H}{3 V_{H}}}\right]\left[\frac{1}{1+\frac{10 n_{o} W}{V_{H}}}\right]
$$

- $C_{e}$ is the exposure factor, which varies for each category and is proportional to $\left(\frac{Z}{Z_{r e f}}\right)^{\alpha}$ where $Z_{r e f}$ is a reference height for the specific terrain category (values of the exposure factor may also be pulled from plots provided in the code);

- and $q$ is the reference velocity pressure given by: 


$$
q=C \bar{V}^{2}
$$

where the factor $C$ is a constant depending on the atmospheric pressure and the air temperature and $\bar{V}$ is the reference wind speed.

RMS accelerations may then be found by dividing the peak acceleration by the peak factor.

The dynamic factor $\left(C_{g}\right)$, or gust factor, is defined as:

$$
C_{g}=1+g_{p}(\sigma / \mu)
$$

where:

$$
(\sigma / \mu)=\sqrt{\frac{K}{C_{e H}}\left(B+\frac{S F}{\beta}\right)}
$$

where $C_{e H}$ is the same exposure factor defined above, simply evaluated at the building height.

Having recognized that, while the primary deflection may be in the alongwind direction, the acrosswind acceleration significantly affects occupant comfort and serviceability, the Canadian Code provides an expression for this acceleration at the top of the building based on a variety of wind tunnel studies. In order to determine the peak acrosswind acceleration, the following formula is provided:

$$
a_{w}=n_{w}^{2} g_{p} \sqrt{W D}\left(\frac{a_{r}}{\rho_{B} g \sqrt{\beta_{W}}}\right)
$$

where previously undefined terms include:

- $n_{w}$ and $\beta_{\mathrm{W}}$, the first modal frequency and ratio of critical damping, respectively, in the acrosswind direction;

- $g$, acceleration due to gravity, taken as $9.8 \mathrm{~m} / \mathrm{s}^{2}$;

- and $a_{r}$, defined as:

$$
a_{r}=78.5 \times 10^{-3}\left[\frac{V_{H}}{n_{w} \sqrt{W D}}\right]^{3.3}
$$

RMS accelerations may then be found by dividing by the peak factor, which, for the Canadian Code, remains unchanged from that calculated in the alongwind direction.

Commentary: A large part of the detailed procedure pulls required values from figures, allowing much room for human error, especially in the $\log -\log$ plots, though, for the most part, exact equations are inset 
on each figure for a more precise analysis. However, to the credit of this code, its authors did recognize the significance of acrosswind response when considering issues of occupant comfort and serviceability and has provided expressions for the acrosswind acceleration to address this. The expressions for the alongwind and acrosswind peak acceleration are both compact and conveniently share many of the same parameters, saving considerable computational effort. The torsional response is neglected, though empirical expressions for the torsional response have been reported by Canadian researchers, but they have not yet been made part of the code.

\subsection{European Prestandard (1995)}

Consistent with the other standards considered, the European Prestandard (European Prestandard 1995) applies quasi-static pressures or forces equivalent to the extreme effects of wind. While two analysis schemes are presented in the prestandard, only the detailed analysis, corresponding to a dynamic factor $\left(C_{d}\right)$, i.e. gust factor, greater than 1.2 , is described herein.

Annex B in the standard contains the detailed analysis, based on the non-dimensional power spectral density function $\left(R_{N}\right)$, for buildings that have an uncoupled alongwind fundamental mode, obey a linear elastic assumption, and fit one of the corresponding standardized cases presented. Otherwise, a wind tunnel analysis must be performed. The annex provides an expression for the RMS acceleration of the building in the alongwind direction:

$$
\sigma_{\ddot{x}}=\frac{\Phi_{1, x}(z) \rho b C_{f} V_{m}^{2}\left(z_{e q u}\right)}{m_{1, x}} I_{v}\left(z_{e q u}\right) R_{x} K_{x}
$$

where:

- $\Phi_{1, x}(z)$ : the fundamental alongwind mode shape, approximated by:

$$
\Phi_{1}(z)=\left(\frac{z}{h}\right)^{\zeta}
$$

with $h$ being the height of the structure and $\zeta$ is the mode exponent;

- $\rho$ : air density;

- $\quad b$ : building width;

- $C_{f}$ : averaged alongwind force coefficient;

- $V_{m}\left(z_{e q u}\right)$, mean wind velocity at the building's equivalent height $(0.6 h)$, but in general:

$$
V_{m}(z)=C_{r}(z) C_{t}(z) V_{r e f}
$$

where $V_{r e f}$ is the reference velocity and $C_{t}(z)$, the topography coefficient, is taken as 1 except in the presence of isolated hills or escarpments, in which case expressions provided in the code must be used, while $C_{r}(z)$, the roughness coefficient may be calculated from relationships based on the roughness length $\left(z_{o}\right)$ and minimum height for a specific terrain; 
- $I_{v}\left(z_{e q u}\right)$, alongwind turbulence intensity at the equivalent height:

$$
I_{v}\left(z_{e q u}\right)=\frac{1}{C_{t}\left(z_{e q u}\right) \ln \left(z_{e q u} / z_{o}\right)}
$$

- $m_{1, x}$ : alongwind fundamental modal mass per unit length, taken for cantilevered structures with slightly varying mass distribution as the average value of the mass per unit length for the upper third of the structure;

- $R_{x}$ is the resonant response part given by:

$$
R_{x}^{2}=\frac{\pi^{2}}{2 \delta} R_{N} R_{h} R_{b}
$$

where $\delta$ is the logarithmic damping decrement of the alongwind vibration, with acceptable values given in the code and $R_{N}$, the non-dimensional power spectral density function, and $R_{h}$ and $R_{b}$, the aerodynamic admittance functions, are given by:

$$
\begin{gathered}
R_{N}=\frac{6.8 N_{1, x}}{\left(1+10.2 N_{1, x}\right)^{5 / 3}} \\
R_{l}=\frac{1}{\eta}-\frac{1}{2 \eta^{2}}\left(1-e^{-2 \eta}\right) \quad \eta>0 \\
R_{l}=1 \quad \eta=0 \\
\text { when: } R_{h}=R_{l} \text { setting } \eta=\frac{4.6 N_{1, x} h}{L_{I}\left(z_{e q u}\right)} \\
\text { and when } R_{b}=R_{l} \text { setting } \eta=\frac{4.6 N_{1, x} b}{L_{I}\left(z_{e q u}\right)} \\
\text { with } N_{1, x}=\frac{n_{1, x} L_{I}\left(z_{e q u}\right)}{V_{m}\left(z_{e q u}\right)}
\end{gathered}
$$

where $n_{l, x}$ is the fundamental natural frequency of the building in the alongwind direction and $L_{I}\left(z_{e q u}\right)$ is the integral length scale of turbulence which depends upon the minimum height and power law exponent for the boundary layer of the terrain category in question.

- and $K_{x}$ is a non-dimensional coefficient approximated by:

$$
K_{x}=\frac{(2 \zeta+1)\left\{(\zeta+1)\left[\ln \left(z_{e q u} / z_{o}\right)+0.5\right]-1\right\}}{(\zeta+1)^{2} \ln \left(z_{e q u} / z_{o}\right)}
$$

where $\zeta$ is the exponent of the mode shape. 
The dynamic (gust) factor is then given by:

$$
C_{d}=\frac{1+2 g I_{v}\left(z_{e q u}\right) \sqrt{Q_{o}^{2}+R_{x}^{2}}}{1+7\left(I_{v}\left(z_{e q u}\right)\right)}
$$

where:

- $g$ : peak factor is given by:

$$
g=\sqrt{2 \ln (\mathrm{v} t)}+\frac{0.6}{\sqrt{2 \ln (\mathrm{v} t)}}
$$

where $t$ is the averaging time of the reference wind velocity $(600 \mathrm{~s})$ and $v$ is the expected frequency:

$$
\begin{gathered}
v=\sqrt{\frac{v_{o}^{2} Q_{o}^{2}+n_{1, x} R_{x}^{2}}{Q_{o}^{2}+R_{x}^{2}}} \\
\text { with } v_{o}=\frac{V_{m}\left(z_{\text {equ }}\right)}{L_{I}\left(z_{\text {equ }}\right)} \frac{1}{1.11 S^{0.615}} \\
\text { where } S=0.46\left(\frac{b+h}{L_{I}\left(z_{\text {equ }}\right)}\right)+10.58\left(\frac{\sqrt{b h}}{L_{I}\left(z_{\text {equ }}\right)}\right)
\end{gathered}
$$

- and $Q_{o}$ is the background response part:

$$
Q_{o}^{2}=\frac{1}{1+0.9\left(\frac{b+h}{L_{I}\left(z_{\text {equ }}\right)}\right)^{0.63}}
$$

The peak acceleration may be found by multiplying the RMS acceleration by the peak factor.

Commentary: The standard is very thorough and has been based on an extensive series of publications utilizing close-form expressions for the gust loading factor. However the calculations required to determine the RMS acceleration in the European Standard involve multiple equations scattered throughout the text. Since expressions are not confined to a particular section, the procedure becomes tedious at times, though the procedure can be performed conveniently once programmed into a spreadsheet. In addition, a shortcoming of this standard is its failure to treat the acrosswind and torsional response.

\subsection{British Standard (1995)}

Consistent with the other standards considered, the British Standard Part 2's (British Standard 1995) Standard method uses equivalent static loads to represent the effect of fluctuating loads for buildings not susceptible to dynamic excitation. The response of mildly dynamic structures may be calculated by the procedure in Annex C; however, British Standard Part 2 is not suggested for buildings taller than $300 \mathrm{~m}$ 
or having calculated dynamic augmentation factors $\left(C_{r}\right)$ greater than 0.25 . The transition into this regime indicates a fully dynamic building, for which the method becomes less accurate and generally more conservative. In such cases, the response should be determined by other appropriate methods, e.g. those described in Engineering Sciences Data Units (ESDU 1989). However, for buildings that are at most mildly dynamic, i.e. $C_{r}<0.25$ and $H<300 \mathrm{~m}$, the following simplified expression for the dynamic augmentation factor, the ratio of actual peak deflection to static peak deflection, may be applied:

$$
C_{r}=\frac{K_{b}\left(H / h_{o}\right)^{0.75}}{800 \log _{10}\left(H / h_{o}\right)}
$$

where $h_{o}$ is taken as $0.1 \mathrm{~m}, H$ is the building height, and $K_{b}=1 /(32 \xi)$, where $\xi$ is the structural critical damping ratio. This expression is a curve fit of figures provided in the standard, which were generated from the full expression for the dynamic augmentation factor. The full expression is a function of the gust factor, based on structural size and surrounding terrain, typically a function of the building's dimensions and location.

Once the design pressure is found by multiplying the reference pressure by an external pressure coefficient and a size effect factor to account for the non-simultaneous action of gusts across the surface, overall loads may be found by:

$$
P=0.85\left(\sum P_{\text {front }}-\sum P_{\text {rear }}\right)\left(1+C_{r}\right)
$$

where $\sum P_{\text {front }}$ is the horizontal component of surface loads summed over the windward walls and roofs and $\sum P_{\text {rear }}$ is likewise for the leeward walls and roofs.

Commentary: The British Standard is very hands on, straightforward standard that provides a means to determine the pressures on buildings for a very simplified approach, with no sufficiently detailed procedure provided. The code only applies to a specific group of structures that are not significantly susceptible to dynamic effects, for which only the alongwind loads are found. Should the target structure exhibit any wind-sensitive characteristics or not fit one of the prescribed building types, the code is no longer valid and an appropriate alternative dynamic analysis must be consulted.

\subsection{ASCE7-95 Standard}

Chapter 6 of the ASCE7 Standard (ASCE Standard 1995) provides a procedure for wind-sensitive structures, while encouraging wind tunnel testing for structures that deviate significantly from a uniform rectangular prism, are highly flexible with low natural frequencies, subject to buffeting by the wake of upwind structures, or are subjected to accelerated flows caused by channeling or local topographic features. Once the wind velocity pressure is determined in a manner common to all the standards, taking into account topographic factors (Chiu and Perry, 1997), application of the gust factor approach may begin.

An expression to determine the gust factor, $\mathrm{G}$, is defined as: 


$$
G=\frac{1+2 g I_{\bar{z}} \sqrt{Q^{2}+R^{2}}}{1+7 I_{\bar{z}}}
$$

where

- $g$, the peak factor, is taken as approximately 3.5 ;

- $I_{\bar{Z}}$ is the intensity of turbulence at height $\bar{Z}$ :

$$
I_{\bar{Z}}=c\left(\frac{33}{\bar{z}}\right)^{1 / 6}
$$

where $\bar{Z}$ is the equivalent height of the structure taken as $60 \%$ of the building height but no less than a minimum value specified in the standard, and $c$ is a constant given in tables in the standard;

- $Q$ is the background response:

$$
Q^{2}=\frac{1}{1+0.63\left(\frac{b+h}{L_{\bar{Z}}}\right)^{0.63}}
$$

where $b$ and $h$ are the width and height, respectively, of the structure and $L_{\bar{Z}}$ is the integral length scale of turbulence at the equivalent height:

$$
L_{\bar{Z}}=l(\bar{z} / 33)^{\varepsilon}
$$

with values of $l$ and $\varepsilon$ provided in appropriate tables.

- and $R$ is the resonant response factor, described by:

$$
\begin{gathered}
R^{2}=\frac{1}{\beta} R_{n} R_{h} R_{b}\left(0.53+0.47 R_{d}\right) \\
R_{n}=\frac{7.465 N_{1}}{\left(1+10.302 N_{1}\right)^{5 / 3}} \\
N_{1}=\frac{n_{1} L_{\bar{Z}}}{\bar{V}_{\bar{Z}}} \\
R_{l}=\left[\begin{array}{cc}
\frac{1}{\eta}-\frac{1}{2 \eta^{2}}\left(1-e^{-2 \eta}\right) & \text { for } \eta>0 \\
1 & \text { for } \eta=0 \\
(l=h, b, d) &
\end{array}\right.
\end{gathered}
$$




$$
\begin{gathered}
R_{l}=R_{h} \text { setting } \eta=4.6 n_{1} h / \bar{V}_{\bar{Z}} \\
R_{l}=R_{b} \text { setting } \eta=4.6 n_{1} b / \bar{V}_{\bar{Z}} \\
R_{l}=R_{d} \text { setting } \eta=15.4 n_{1} d / \bar{V}_{\bar{Z}}
\end{gathered}
$$

where $\beta$ is the damping ratio and $\bar{V}_{\bar{z}}$ mean hourly wind speed at height $\bar{Z}$ described by:

$$
\bar{V}_{\bar{Z}}=\bar{b}\left(\frac{\bar{z}}{33}\right)^{\bar{\alpha}} \hat{V}_{r e f}
$$

where $\hat{V}_{\text {ref }}$ is the reference wind velocity (3 second gust in open terrain at $10 \mathrm{~m}$ ) and values of $\bar{\alpha}$ and $\bar{\beta}$ are provided in appropriate tables.

Though the gust factor of ASCE7 is similar to the dynamic factor in the European Standard, it is clear that each standard has distinct expressions to determine the parameters involved due to differences in the averaging period of the wind. The RMS acceleration is then given by:

$$
\sigma_{\ddot{x}}(z)=\frac{0.85 \phi(z) \rho b h C_{f x} \bar{V}_{\bar{z}}^{2}}{m_{1}} I_{\bar{Z}} K R
$$

where previously undefined terms include:

- $\rho:$ density of air;

- $C_{f x}$ : the mean alongwind force coefficient;

- $\phi(z)$ : the fundamental mode shape, given by:

$$
\phi(z)=\left(\frac{z}{h}\right)^{\xi}
$$

where $\xi$ is the mode exponent.

- $m_{l}$ : the modal mass, approximated as:

$$
m_{1}=\int_{0}^{h} \mu(z) \phi^{2}(z) d z
$$

where $\mu(z)$ is the mass per unit height of the building;

- and $K$ :

$$
K=\frac{(1.65)^{\hat{\alpha}}}{\hat{\alpha}+\xi+1}
$$

where values of $\hat{\alpha}$ are provided in tables in the standard. 
Further information regarding the provisions contained in ASCE7 may be found in Solari \& Kareem (1997), Simiu \& Stathopoulos (1997), and Chiu \& Perry (1997).

Commentary: The ASCE7 Standard is easy to follow with charts and tables making values readily available without the extensive use of plots to determine values. The use of closed from expressions for the gust factor makes this procedure very attractive for implementation on spreadsheets. Since each of the three procedures only changes the gust factor, leaving the heart of the analysis essentially unchanged, the authors wisely place these alternative procedures for finding the gust factor in the commentary so not to confuse the user. The ASCE7 Standard may be criticized, however, like many of the other standards, for neglecting the acrosswind and torsional response of the structure. Their treatment in the standard has been omitted due to the lack of consensus among committee members regarding the need for such provisions.

\subsection{China National Standard}

While the China National Standard (China National Standard 1987) will not be treated here in full, a brief discussion of its treatment of its analogous dynamic response factor is presented, in light of its application to a region witnessing a rapid increase in the number of tall buildings coupled with the frequent threat of extreme typhoon winds. A simplified expression for the dynamic response factor, $\beta$, applied in Chinese code is given by:

$$
\beta_{Z}=1+\xi v \varphi_{Z} / \mu_{Z}
$$

where:

- $\xi$ is the magnification factor of the wind fluctuation, which depends on the power density spectrum of wind speed and the properties of the structural vibration. The code applies the empirical equation of power spectral density suggested by Davenport (1967);

- $\quad v$ is the wind turbulence and correlation factor which accounts for the "turbulence density" and the spatial correlation of the wind;

- $\mu_{Z}$ is the exposure factor at height $z$ defined as:

$$
\mu_{Z}=C\left(\frac{z}{10}\right)^{2 \alpha}
$$

in which the constant $C$ and the power $\alpha$ will vary depending on the terrain category of interest;

- $\quad$ and $\varphi_{\mathrm{Z}}$ is the mode shape factor of vibration which, for buildings, may be taken as:

$$
\varphi_{Z}=\operatorname{tg}\left[\frac{\pi}{4}\left(\frac{z}{H}\right)^{0.7}\right]
$$

where $H$ is the total height of the building and the values of remaining parameters may be taken from tables provided in the code. 


\subsection{Experimental Procedure}

The lack of torsional and acrosswind descriptions in many international codes and standards, including ASCE7, has prompted the present research effort to develop such relationships. The research at the University of Notre Dame is based upon wind tunnel testing, conducted previously by the second author. The bank of response spectra produced by this study gives an insight into the effects of aspect ratio and crosssection on structural response, especially in the acrosswind and torsional directions, from which an empirical expression for the acrosswind and torsional response may be determined for use in preliminary design.

\subsection{Building Models}

As shown by Fig. 1 below, 9 building cross sections were considered, representing a host of typical building shapes. Three different rigid balsa wood models of each of the 9 building cross-sections were constructed, with heights of 16, 20 and 24 inches, yielding 27 different model buildings of varying aspect ratio and shape, providing some indication of the influence of these factors on aerodynamic loads (Kareem 1992). Fig. 2 illustrates some of these models, (the center building with variable cross-section and openings belongs to the second phase of this study). The light-weight models were then affixed to an ultra-sensitive force balance and subjected to wind tunnel testing.

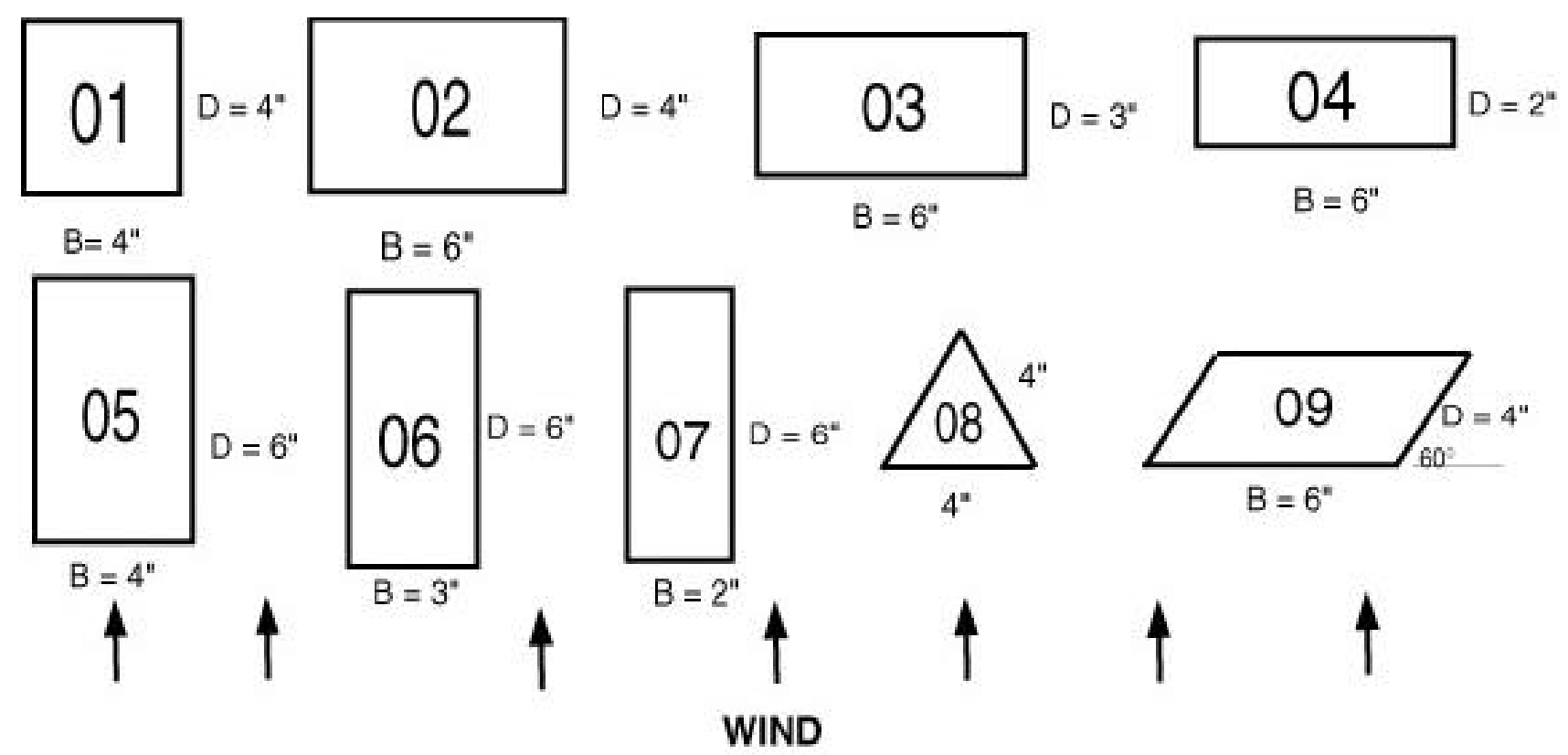

FIGURE 1. Building cross-sections considered in the study. 


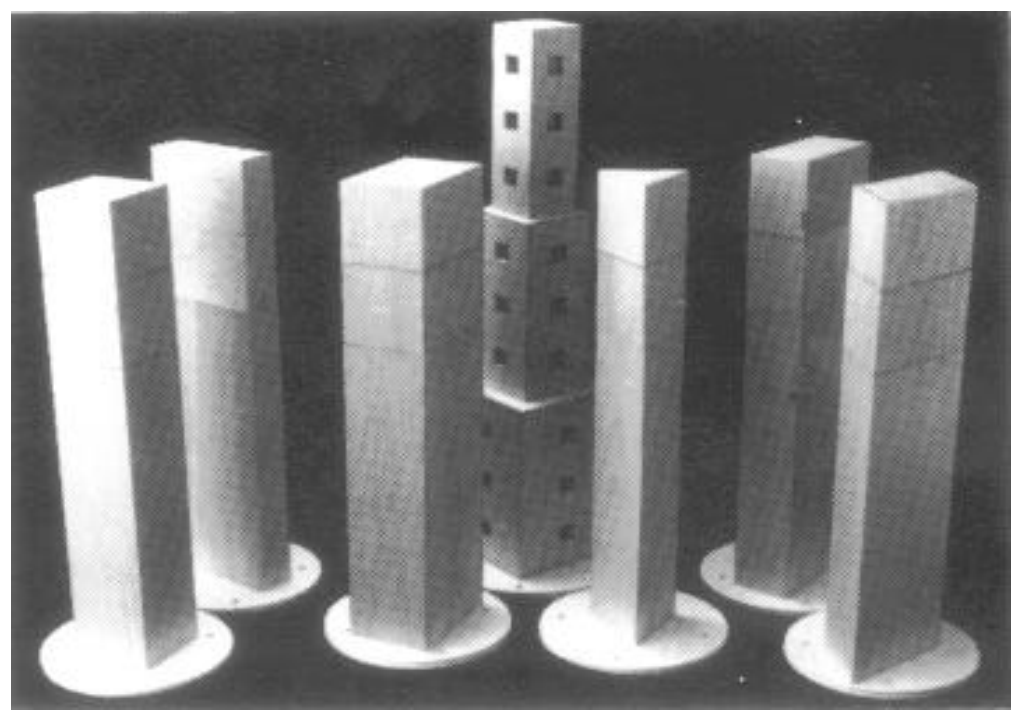

FIGURE 2. Photograph of some of the balsa wood models used in this study.

\subsection{Force-Balance Approach/Mode Shape Corrections}

A high-frequency force balance may be used for determining the dynamic wind-induced structural loads from scale models of buildings and structures (e.g. Kareem \& Cermak 1979, Tschanz \& Davenport 1983, Reinhold \& Kareem 1986 and Boggs \& Peterka 1989. These techniques have dramatically reduced both the time and cost required to obtain estimates of wind loads and structural response levels. The force balance provides dynamic load information for a specific building geometry and setting which maybe used to calculate loads and response levels for a wide range of structural characteristics, damping values, and building masses. The force balance technique has some shortcomings, e.g. only approximate estimates of the mode-generalized torsional moments are obtained and the lateral loads may be inaccurate if the sway mode shapes of the structure deviate significantly from a linear mode shape. A second generation of force balances permits overcoming the aforementioned limitations (Reinhold \& Kareem 1986).

The aerodynamic loads on buildings may be obtained by mapping and synthesizing the random pressure fields acting on the building envelope. The structure of random pressure fields through simultaneously monitored multiple-point realizations of pressure fluctuations and measurement of the local averages of the space-time random pressure fields by means of spatial and temporal averaging techniques can be mapped (e.g. Kareem 1989). The pressure-based force measurement scheme does not suffer from the mode shape restrictions associated with the base-balance approach, as the user is free to introduce any desired mode shape.

The loads obtained by the force-balance approach or multi-point pressure measurements do not include motion-induced aerodynamic loads. It is general consensus that in most tall buildings the influence of motion-induced loading is significant for typical design wind speeds. For exceptionally slender, flexible 
and lightly damped structures, one may resort to aeroelastic models or use special motion-induced force measurement systems in conjunction with a force balance.

The force-balance-measured fluctuating base bending moment has a power spectral density given by:

$$
S_{M}(f)=\int_{0}^{H} \int_{0}^{H} S_{P}\left(z_{1}, z_{2} ; f\right) z_{1} z_{2} d z_{1} d z_{2}
$$

where $z$ is the height above the base level, $S_{P}\left(z_{1}, z_{2} ; f\right)$ represents the cross spectral density of the aerodynamic load per unit height at $z_{1}, z_{2}$ and frequency $f$, and $H$ is the building height. The mode generalized force spectrum on the building is given by:

$$
S_{F}(f)=\int_{0}^{H} \int_{0}^{H} S_{P}\left(z_{1}, z_{2} ; f\right) \phi\left(z_{1}\right) \phi\left(z_{2}\right) d z_{1} d z_{2}
$$

where $\phi(z)$ is the normalized mode shape $(\phi(H)=1)$. It is clear that for a linear mode shape, $\phi(z)=z / H$, and the preceding descriptions are related by:

$$
S_{F}(f)=\frac{1}{H^{2}} S_{M}(f)
$$

Thus, a force-balance provides a convenient measure of the generalized force associated with a linear mode shape. While this assumption of a linear mode shape is true for both the alongwind and acrosswind directions, in the case of torsional data acquisition, the force-balance provides spectrum consistent with a uniform mode shape. Therefore, appropriate mode shape corrections are necessary in the case of torsion and when the sway modes depart from a linear mode shape (Kareem 1984; Vickery et al 1985; Boggs \& Peterka 1989; Katagiri et al 1992).

Following Eq. (87), the correction for the generalized force spectrum can be made by the following:

$$
\psi^{2}=\frac{\int_{0}^{H} \int_{0}^{H} S_{P}\left(z_{1}, z_{2} ; f\right)\left(\phi\left(z_{1}\right)\right)^{\alpha}\left(\phi\left(z_{2}\right)\right)^{\alpha} d z_{1} d z_{2}}{\int_{0}^{H} \int_{0}^{H} S_{P}\left(z_{1}, z_{2} ; f\right)\left(\phi\left(z_{1}\right)\right)^{\beta}\left(\phi\left(z_{2}\right)\right)^{\beta} d z_{1} d z_{2}}
$$

where $\psi^{2}$ is the correction factor to adjust a measured spectrum weighted with mode shape $\left(\phi\left(z_{1}\right)\right)^{\beta}$ to the desired mode shape $\left(\phi\left(z_{1}\right)\right)^{\alpha}$, and the cross spectral density can be replaced by its normalized description, i.e. coherence function. In the case of force-balance measurements of lateral and torsional loads, $\beta=1$ and 0 , respectively.

In the case of alongwind analysis, quasi-steady and strip theories are typically invoked, permitting the substitution of the incident velocity cross spectral density, $S_{U}\left(z_{1}, z_{2} ; f\right)$, or its corresponding coherence $R_{U}\left(z_{1}, z_{2} ; f\right)$, for $S_{P}\left(z_{1}, z_{2} ; f\right)$, or its coherence $R_{P}\left(z_{1}, z_{2} ; f\right)$, in the preceding expressions. In the acrosswind and torsional directions, $R_{P}\left(z_{1}, z_{2} ; f\right)$, like $R_{U}\left(z_{1}, z_{2} ; f\right)$, can be expressed in exponential form: 


$$
R\left(z_{1}, z_{2} ; f\right)=\exp \left(-C f \frac{\left|z_{1}-z_{2}\right|}{U_{H}}\right)
$$

Experimental investigation suggests that the value of $C$ for area-averaged loads measured at several levels along the building height varies between 5 and 9 (Kareem 1990). Similar observations have been reported by Katagiri et al (1992). Analysis shows that correction factor $\psi^{2}$ is not very sensitive to small changes in $C$ falling within this range.

\subsection{Wind Tunnel}

Each of the balsa models was tested in a boundary layer wind tunnel with a $10 \mathrm{ft}(3 \mathrm{~m}) \times 5 \mathrm{ft}(1.5 \mathrm{~m})$ cross-section, of $60 \mathrm{ft}(18 \mathrm{~m})$ length (Kareem 1990). The turbulent boundary layers simulated in this study were generated by the natural action of the surface roughness added on the tunnel floor and the upstream spires. Two typical boundary layers were simulated in this study, BLI and BLII, similar to the conditions of open and urban flow environments, respectively. As illustrated by Fig. 3, in BLI $(\alpha=0.16)$ there is less variation of the incident mean velocity along the model elevation accompanied by a lower intensity of turbulence in comparison with BLII $(\alpha=0.35)$. The longitudinal length scale between the heights of 10 in. $(25.4 \mathrm{~cm})$ to 30 in. $(76.2 \mathrm{~cm})$ varied from 12 in. $(30.5 \mathrm{~cm})$ to 20 in. $(50.8 \mathrm{~cm})$. A constant-temperature hot-film was used to map the flow field characteristics in the tunnel.
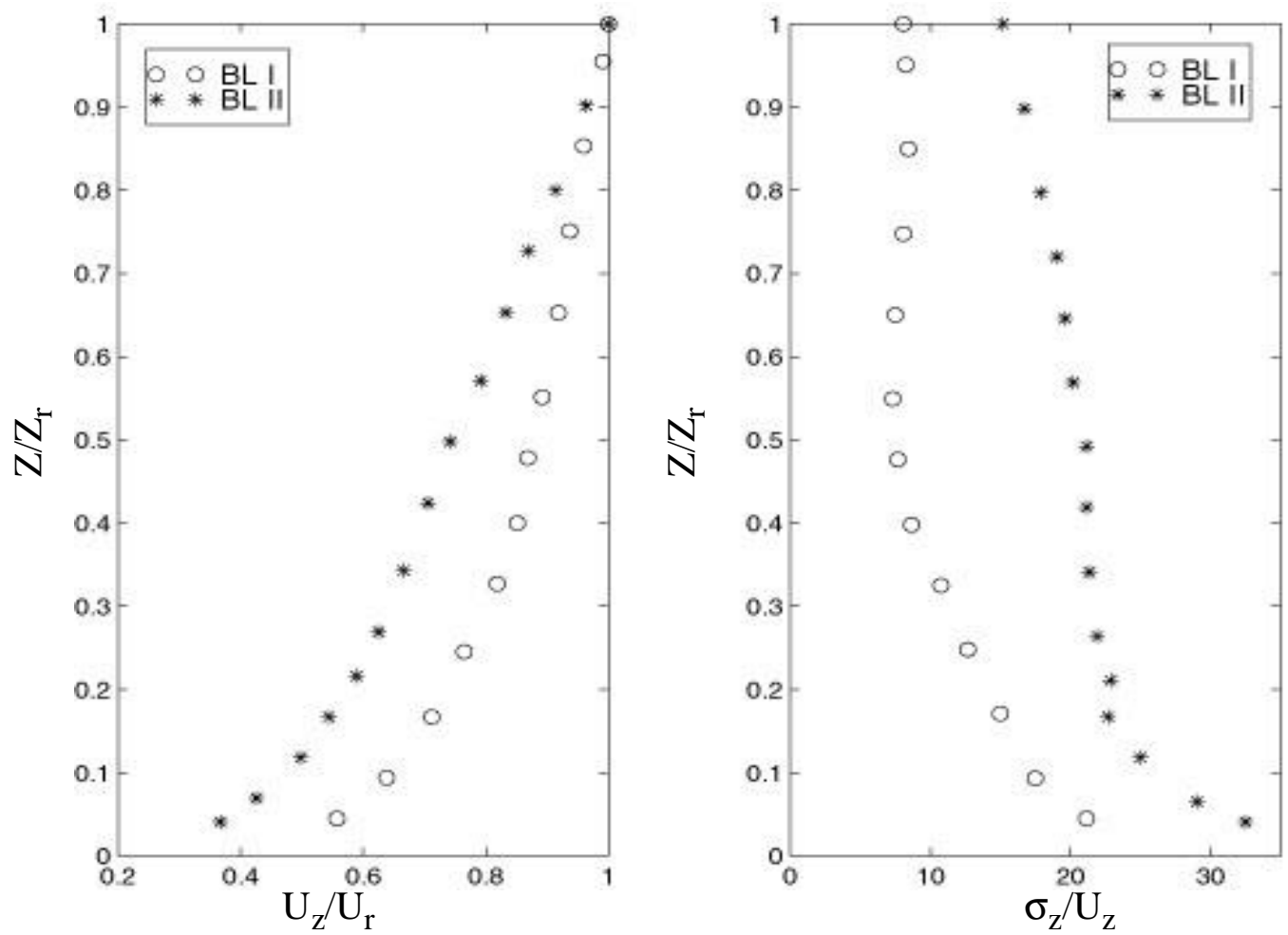

FIGURE 3. Boundary layer and turbulence intensity profiles. ( $r=1 \mathrm{~m}, \alpha=0.16$ and 0.35 , respectively) 


\subsection{Data Analysis}

The output of the sensitive, multi-component force balance was analyzed, using the FFT, to determine the spectral and cross-spectral density functions which were later non-dimensionalized. This analysis was carried out for all 27 model buildings, in both boundary layers, and at varying angles of wind incidence, though only the case of $\theta=0^{\circ}$ will be considered here.

A validation of the measured acrosswind spectra was conducted with a model for the acrosswind force on buildings found in Kareem (1989) based on earlier measurements at a different wind tunnel. The measurements reported here almost agreed perfectly with this model. In addition, a confirmation of the results for the torsional loads was also conducted by comparing the sensitive force balance results, with those found by another technique: pneumatic averaging (Kareem 1990). This latter technique measures torsional loads by pneumatically averaging the pressure measurements at five levels on the model face, with the pressure taps clustered on the model to account for the weighting function needed to introduce the lever arm for torsional response measurements. Further details may be found in Kareem (1989). Using this approach, the torsional loads were obtained at the different levels simultaneously and later synthesized to obtain integral loads according to a desired mode shape (a uniform mode shape was considered for this comparison). The measured, mode generalized spectra were compared to those obtained from the sensitive high-frequency force balance. As Fig. 4 illustrates, there is good agreement between the two force measurement approaches, implying the validation of the spatial averaging technique discussed in Kareem (1990). The minor discrepancy in the high frequency range is not significant for typical design applications and may be corrected by increasing the number of clusters of tap matrices in the pneumatic averaging case to account for pressure fluctuations associated with short wavelengths.

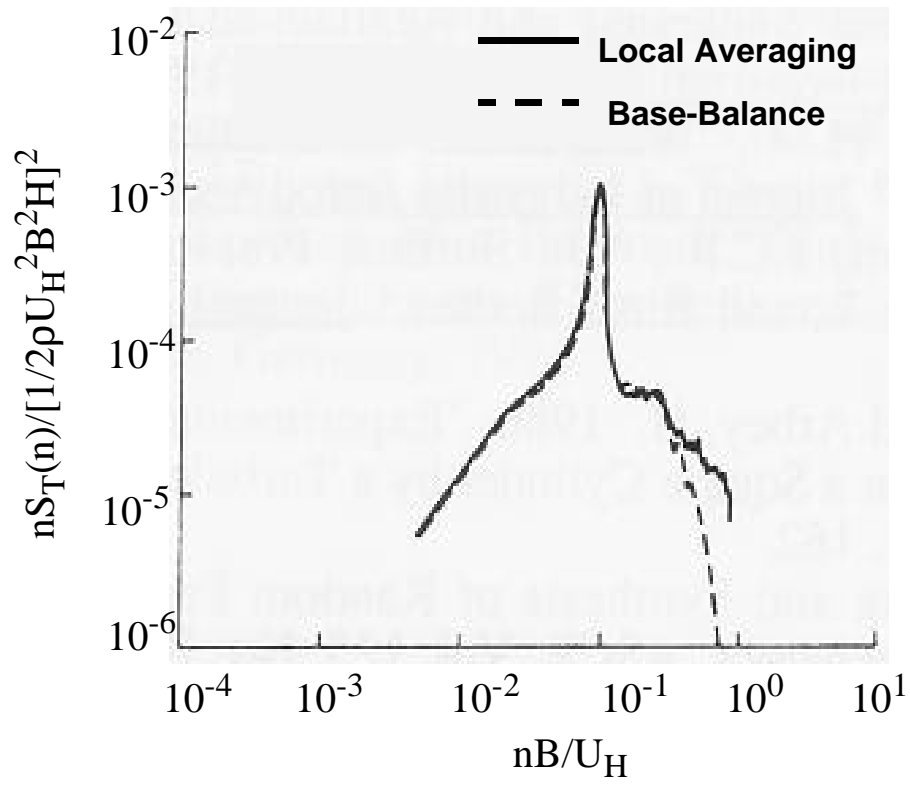

FIGURE 4. Comparison of torsional load spectra utilizing pneumatic averaging and force balance techniques. 


\subsection{Modeling of Load Spectra}

At the time of analysis, only the spectral plots were available and thus had to be digitized using a software package, Digimatic $^{\mathrm{TM}}$, so that the data points could be fitted with a curve of the following form:

$$
Y(x)=\sum_{j=1}^{N}\left\{\frac{C_{j} K_{j}\left(1+0.6 \beta_{j}\right) \beta_{j}}{\pi}\left[\frac{\left(x / f_{j}\right)^{A_{j}}}{\left\{1-\left(x / f_{j}\right)^{2}\right\}^{2}+4 \beta_{j}\left(x / f_{j}\right)^{2}}\right]\right\}
$$

where $Y(\mathrm{x})$ is the non-dimensionalized spectral density and $x$ is the non-dimensionalized frequency on the plots, $N$ corresponds to the number of peaks in the spectra, and the remaining parameters are varied to insure the best possible curve fit. This expression represents a transfer function of a linear damped system. The summation is introduced to account for spectral descriptions with double peaks. A similar expression has been applied by AIJ. By varying the parameters of this equation, accurate curve fits may be obtained, an example of which is shown in Fig. 5. Note that Fig. 5(a) shows the original non-dimensionalized spectra (solid line) and Fig. 5(b) shows the data points returned by Digimatic ${ }^{\mathrm{TM}}$ (circles) and the resulting curve fit (solid) obtained by Eq. (91). A data base of the empirical curve fits for the alongwind, acrosswind, and torsional response spectra for each of the 27 buildings tested in both an urban and suburban terrain has been generated by this approach.

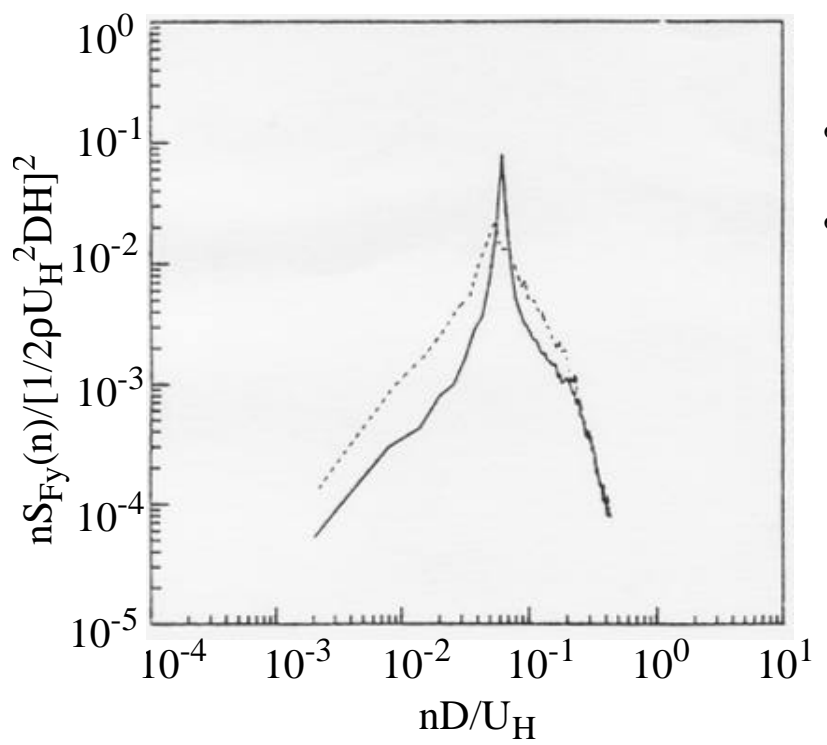

(a)

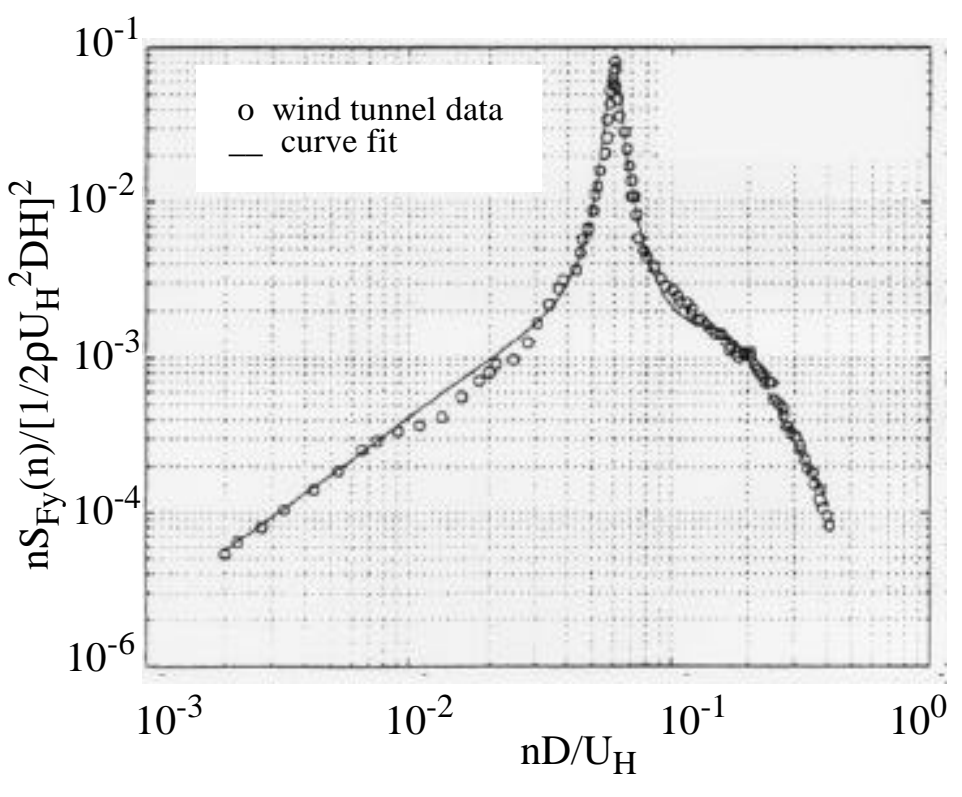

(b)

FIGURE 5. (a) Example spectra obtained from wind tunnel study (BL I: solid, BL II: dashed) (b) Digitization of BL I spectra and resulting curve fit. 


\subsection{Comparison of Codes and Standards with Wind Tunnel Data}

While the resulting data and spectra are too numerous to present here, a comparison of the gust factor determined by each standard was determined for a sample building shown in Fig. 6, accompanied by its relevant structural data. Then, a comparison of each standard against wind tunnel data was conducted, using the RMS accelerations as an indicator. For this comparison, the alongwind, acrosswind, and torsional RMS accelerations determined by each standard, using three reference velocities: 3-second gusts of 70, 75, 80, and $90 \mathrm{mph}$, at $10 \mathrm{~m}$ above ground in an open terrain, are analyzed versus the response determined by the wind tunnel data. While the reference velocities used in the example meet all the standards' criteria for terrain conditions and measurement height, a valid comparison can only be made by adjusting each reference velocity for the appropriate gust duration specified in each standard. Since other standards may use mean hourly and 10 minute gusts for their reference wind velocities, Table 1 contains the appropriate reference velocities, adjusted for gust duration, that must be used in the analysis. Using these adjusted reference velocities and the most detailed dynamic procedure offered by each standard, estimates of the peak and RMS accelerations were calculated for the alongwind, acrosswind, and torsional directions. Where expressions for the RMS accelerations were lacking, values were obtained through dividing the peak acceleration by a peak factor. Values for the alongwind response for the British Standard were not provided, since they must be obtained from another source once the force distribution on the building is obtained. The China National Code will also be omitted from this comparison since only general details of its provisions were presented for informative purposes.

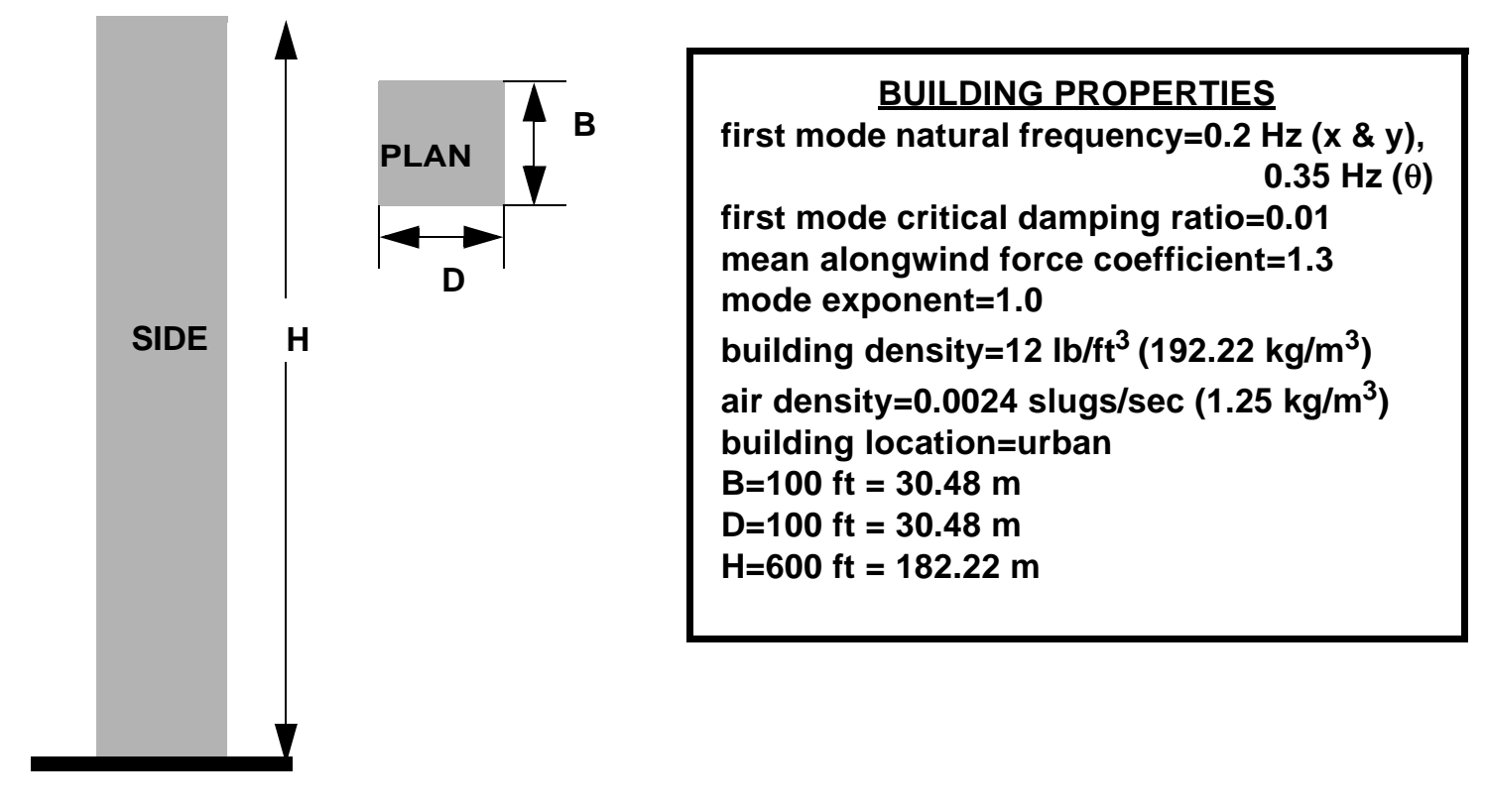

FIGURE 6. Model building used for comparison of international standards. 
TABLE 1. Wind Velocities at $10 \mathrm{~m}$ in Open Terrain for Various Averaging Intervals

\begin{tabular}{|c|c|c|c|c|c|c|c|c|}
\hline \multirow{2}{*}{$\begin{array}{c}\text { Gust } \\
\text { Duration } \\
\text { (Applicable Codes) }\end{array}$} & \multicolumn{2}{|c|}{$\mathrm{V}_{1}$} & \multicolumn{2}{|c|}{$V_{2}$} & \multicolumn{2}{|c|}{$\mathbf{V}_{3}$} & \multicolumn{2}{|c|}{$\mathbf{V}_{4}$} \\
\hline & [mph] & {$[\mathbf{m} / \mathbf{s}]$} & [mph] & {$[\mathbf{m} / \mathbf{s}]$} & {$[\mathrm{mph}]$} & {$[\mathrm{m} / \mathrm{s}]$} & {$[\mathrm{mph}]$} & {$[\mathrm{m} / \mathrm{s}]$} \\
\hline $\begin{array}{l}\text { Reference Velocity: } 3 \mathrm{~s} \\
\text { (ASCE7, Australia) }\end{array}$ & $\overline{770.00}$ & 31.29 & $\begin{array}{l}75.00 \\
\end{array}$ & 33.53 & 80.00 & 35.76 & $\overline{90.00}$ & 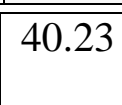 \\
\hline $\begin{array}{c}10 \text { minutes } \\
\text { (AIJ, China, Eurocode) }\end{array}$ & 49.13 & 21.96 & 52.17 & 23.52 & 56.13 & 25.09 & 63.20 & 28.25 \\
\hline $\begin{array}{c}1 \text { hour } \\
\text { (UK, Canada, Australia*) }\end{array}$ & 45.91 & 20.52 & 49.22 & 22.00 & 52.46 & 23.45 & 59.06 & 26.40 \\
\hline
\end{tabular}

The RMS accelerations in all three directions were determined from the wind tunnel data by the following expression:

$$
\sigma=\sqrt{\frac{\pi f_{n} S\left(f_{n}\right)}{4 \xi_{n} M_{n}^{2}}}
$$

where $f_{n}$ is the natural frequency, $\xi_{n}$ is the damping ratio, and $M_{n}$ is the modal mass, each in the $n$-th mode of the structure. $S\left(f_{n}\right)$ is the one-sided spectral density evaluated at the natural frequency. For the purposes of this analysis, only the first mode was considered, in which case $M_{1}$ may be estimated as the total mass $(m)$ of the structure divided by 3 for the acrosswind and alongwind RMS acceleration. In the analysis of torsional response, however, this modal mass term must be replaced by the modal mass moment of inertia determined by: $\frac{1}{12} M_{n}\left(B^{2}+D^{2}\right)$. In addition, the torsional analysis requires the multiplication of the spectral density by a reduction factor to account for the assumption of a constant mode shape, as discussed previously in section 3.2 .

The values of the spectral density were pulled from Fig. 7(a-c), which contains the alongwind, acrosswind and torsional response spectra for the square building examined in this study simulated in the urban boundary layer (BL II). While wind tunnel data was recorded for several incident angles of wind, as Fig. 7 illustrates, only the spectra corresponding to $\theta=0^{\circ}$ is examined in this study. Both the frequency and spectral density have been normalized in these plots, and thus must be multiplied by the normalizing parameters to obtain the required spectral density. 


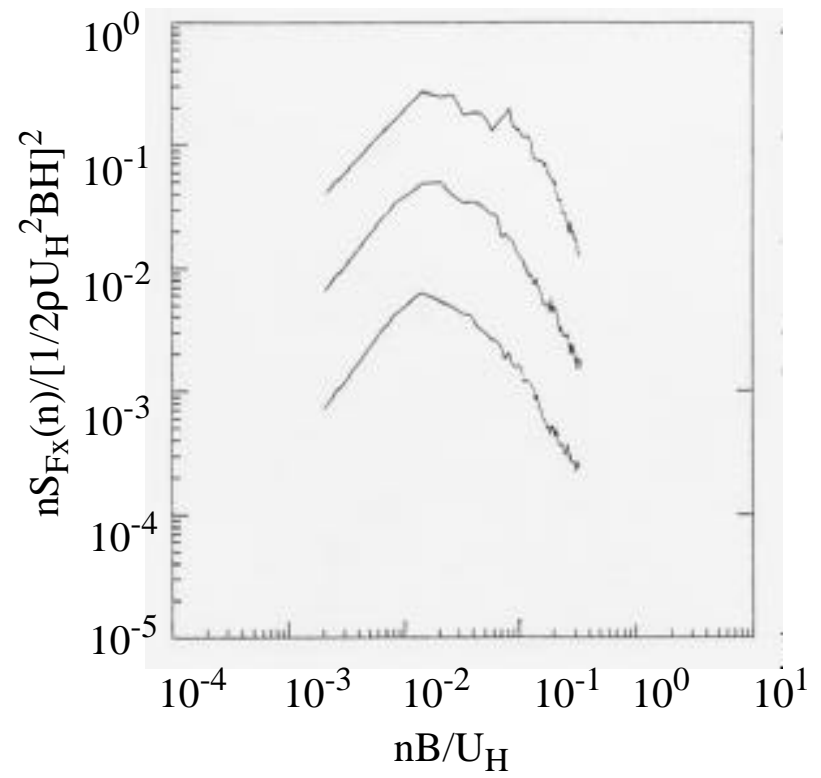

(a)

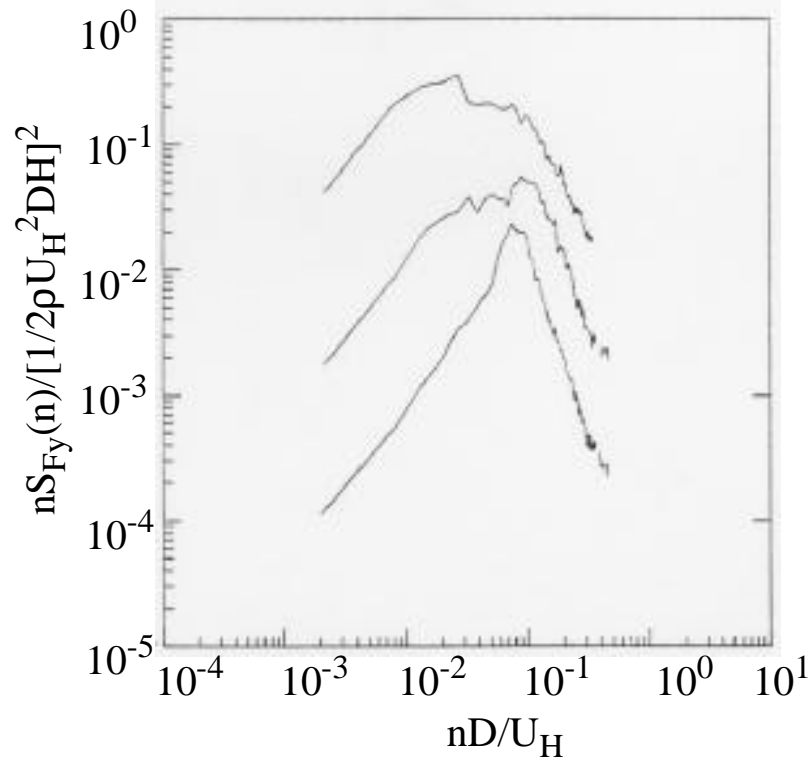

(b)

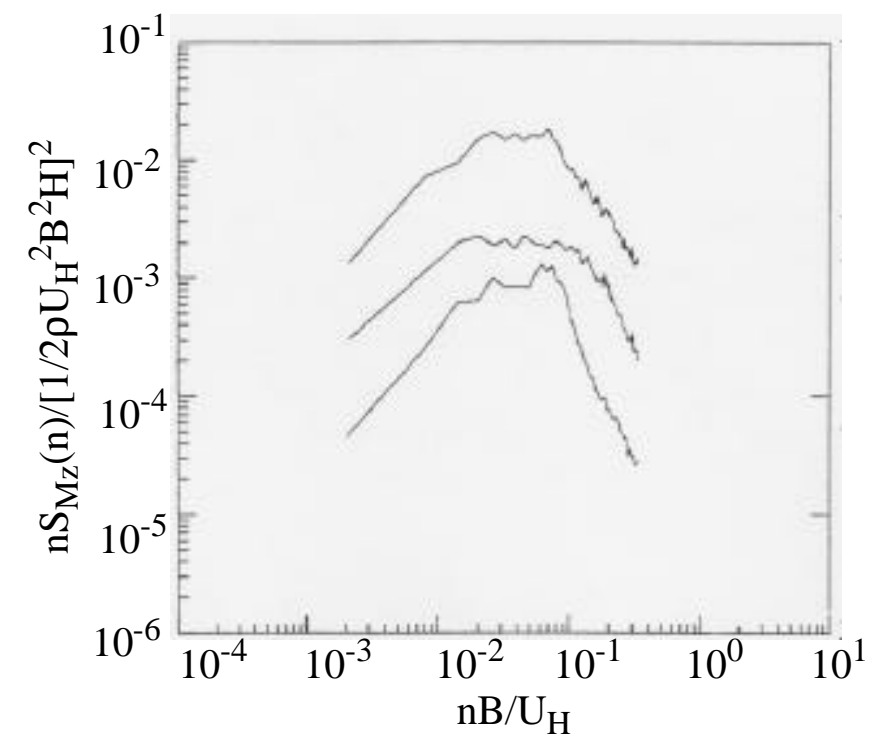

(c)

FIGURE 7. (a) Alongwind; (b) Acrosswind; (c) Torsional response of square building (with aspect ratio 6:1:1) as determined from wind tunnel testing in BL II.

In order for an adequate comparison with the predictions of codes and standards, the 3 second gust analysis velocities used for this study $(70,75,80,90 \mathrm{mph}$ ) measured $10 \mathrm{~m}$ above ground in an open condition must be translated to the equivalent velocity which would occur at the building height in the urban exposure of interest, providing $U_{H}$ applied in the normalization. This was accomplished by using power law 
relationships to bring the analysis velocities (referenced at $10 \mathrm{~m} \approx 33 \mathrm{ft}$ ) to the gradient height in open terrain $(900 \mathrm{ft})$ and then translate them down to the building height $(600 \mathrm{ft})$ in the urban terrain.
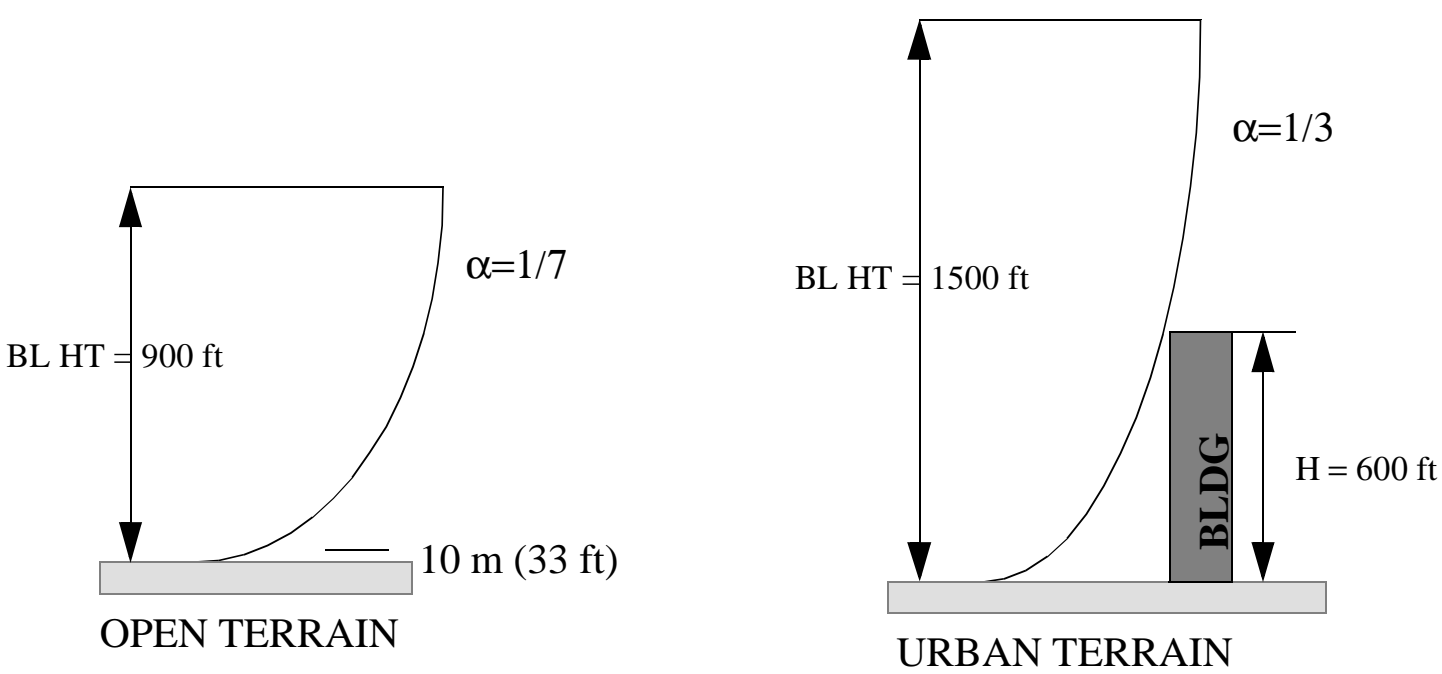

FIGURE 8. Translation of analysis wind velocity in open terrain to urban terrain.

As Fig. 8 indicates, a mean hourly wind velocity $\left(U_{33 \mathrm{ft}}\right)$ at $10 \mathrm{~m}(33 \mathrm{ft})$ in open terrain, can be projected to an equivalent velocity at the gradient height, or mean wind velocity, $(\bar{U})$ through the following relationship:

$$
\frac{U_{33 f t}}{\bar{U}}=\left(\frac{33}{900}\right)^{1 / 7}
$$

This mean wind velocity may then be used to determine the wind speed at the building height in the urban terrain $\left(U_{H}\right)$, through the following relationship:

$$
\frac{U_{H}}{\bar{U}}=\left(\frac{600}{1500}\right)^{1 / 3}
$$

Finally, since only the Japanese Standard contains an expression for the torsional response of the structure, the torsional comparison between the standard and wind tunnel data was cross-checked against an existing empirical relationship developed at the Boundary Layer Wind Tunnel Laboratory at the University of Western Ontario (UWO) (Greig 1980) with complete details given in (Simiu \& Scanlan 1996). The peak angular acceleration is given by:

$$
\ddot{\theta} \approx \frac{2 g_{T} T_{r m s}}{\rho_{b} b d h r_{m}^{2}}
$$

where

- $g_{T}$ is a torsional peak factor, taken as 3.8 ; 
- $\quad b, d$, and $h$ are the building width, depth, and height, respectively;

- $\rho_{b}$ is the density of the building;

- $T_{r m s}$ is the RMS base torque described by:

$$
T_{r m s}[U(h)] \approx \frac{0.00167}{\xi_{T}^{1 / 2}} \rho L^{4} h n_{T}^{2} U_{r}^{2.68}
$$

where $U(h)$ is the wind speed at the top of the building, $\rho$ is the density of the air, $n_{T}$ and $\xi_{T}$ are the natural frequency and the damping ratio in the fundamental torsional mode of vibration, respectively, and

$$
L=\frac{\int|r| d s}{A^{1 / 2}}
$$

with $d s$ being the elemental length of the building perimeter, $|r|$ being the torque arm of the element $d s$, and $A$ is the cross-sectional area of the building, and

$$
U_{r}=\frac{U(h)}{n_{T} L}
$$

- $r_{m}$ is the radius of gyration, which, for a rectangular shape with uniform bulk mass per unit volume, may be approximated by $r_{m}^{2}=\frac{b^{2}+d^{2}}{12}$.

\subsection{Discussion}

\subsection{Gust Factors}

As illustrated by Table 2, the gust factors determined from the Australian Code and ASCE7 form the upper and lower limits, respectively, of the standards examined by this study. This trend is consistent with the comment made in section 2.1 regarding the variation of the gust factor with the averaging time of the reference wind speed. Considering that ASCE7 bases calculations upon a 3 second gust, it should not be surprising that this leads to gust factors close to unity. In the case of the Australian Standard, the use of mean hourly winds in subsequent calculations requires gust factors greater than unity. For the most part, the gust factors show only marginal increases with increased velocity, with exception of the Canadian Standard, whose values begin below the AIJ and Eurocode at low velocities, but markedly increase, approaching the AIJ standard at high velocities 
TABLE 2. Calculated Gust Factors for International Codes \& Standards

\begin{tabular}{|c|c|c|c|c|c|c|}
\hline \multicolumn{2}{|c|}{ Code/Standard } & ASCE7-95 & Australia* & Eurocode & Canada & AIJ \\
\hline \multicolumn{2}{|c|}{ Gust Duration } & $3 \mathrm{sec}$ & $3600 \mathrm{sec}$ & $600 \mathrm{sec}$ & $3600 \mathrm{sec}$ & $600 \mathrm{sec}$ \\
\hline \multirow{4}{*}{$\begin{array}{l}\text { Reference } \\
\text { Velocity }\end{array}$} & $\mathrm{V}_{4}$ & 1.05 & 2.95 & 1.78 & 2.96 & 2.20 \\
\hline & $\mathrm{V}_{3}$ & 1.02 & 2.87 & 1.76 & 2.78 & 2.12 \\
\hline & $\mathrm{V}_{2}$ & 1.01 & 2.83 & 1.71 & 2.70 & 2.08 \\
\hline & $\mathrm{V}_{1}$ & 0.975 & 2.80 & 1.72 & 2.61 & 2.05 \\
\hline
\end{tabular}

\subsection{Alongwind Response}

As expected, these trends manifested in the gust factor also translate to the calculated alongwind RMS accelerations (Table 3). Fig. 9 displays the RMS accelerations for the alongwind and acrosswind directions, where applicable. Notice that ASCE7-95 and AIJ most closely match the alongwind RMS acceleration predicted by the wind tunnel data. It is not surprising that the European and ASCE7 results closely parallel each other, since their procedure for estimating alongwind acceleration response is based on similar theoretical considerations. In light of this, the Australian Standard appears to overestimate the RMS acceleration, while the Canadian Standard begins to deviate from the wind tunnel data at higher velocities, which may be due to negative aerodynamic damping.

TABLE 3. Comparison of Calculated Peak and RMS Alongwind Accelerations from International Codes \& Standards with Wind Tunnel Data.

\begin{tabular}{|c|c|c|c|c|c|c|c|}
\hline & $\begin{array}{c}\text { Ref } \\
\text { Velocity } \\
\text { [mph] }\end{array}$ & $\begin{array}{c}\text { ASCE7- } \\
95\end{array}$ & Australia & Eurocode & Canada & AIJ & $\begin{array}{c}\text { Wind } \\
\text { Tunnel } \\
\text { Data }\end{array}$ \\
\hline \multirow{4}{*}{$\begin{array}{l}\text { Alongwind } \\
\text { Peak } \\
\text { Acceleration } \\
\text { [milli-g's] }\end{array}$} & 90 & 22.30 & 31.65 & 21.78 & 28.80 & 19.84 & 21.59 \\
\hline & 80 & 15.76 & 24.36 & 15.46 & 20.19 & 14.16 & 15.05 \\
\hline & 75 & 13.70 & 21.14 & 12.79 & 16.49 & 11.77 & 12.81 \\
\hline & 70 & 10.34 & 18.18 & 10.45 & 13.33 & 9.66 & 10.71 \\
\hline \multirow{4}{*}{$\begin{array}{l}\text { Alongwind } \\
\text { RMS } \\
\text { Acceleration } \\
\text { [milli-g's] }\end{array}$} & 90 & 5.90 & 8.73 & 6.81 & 7.68 & 6.04 & 6.17 \\
\hline & 80 & 4.16 & 6.72 & 4.86 & 5.39 & 4.31 & 4.30 \\
\hline & 75 & 3.62 & 5.83 & 4.03 & 4.41 & 3.58 & 3.66 \\
\hline & 70 & 2.73 & 5.01 & 3.30 & 3.57 & 2.94 & 3.06 \\
\hline
\end{tabular}



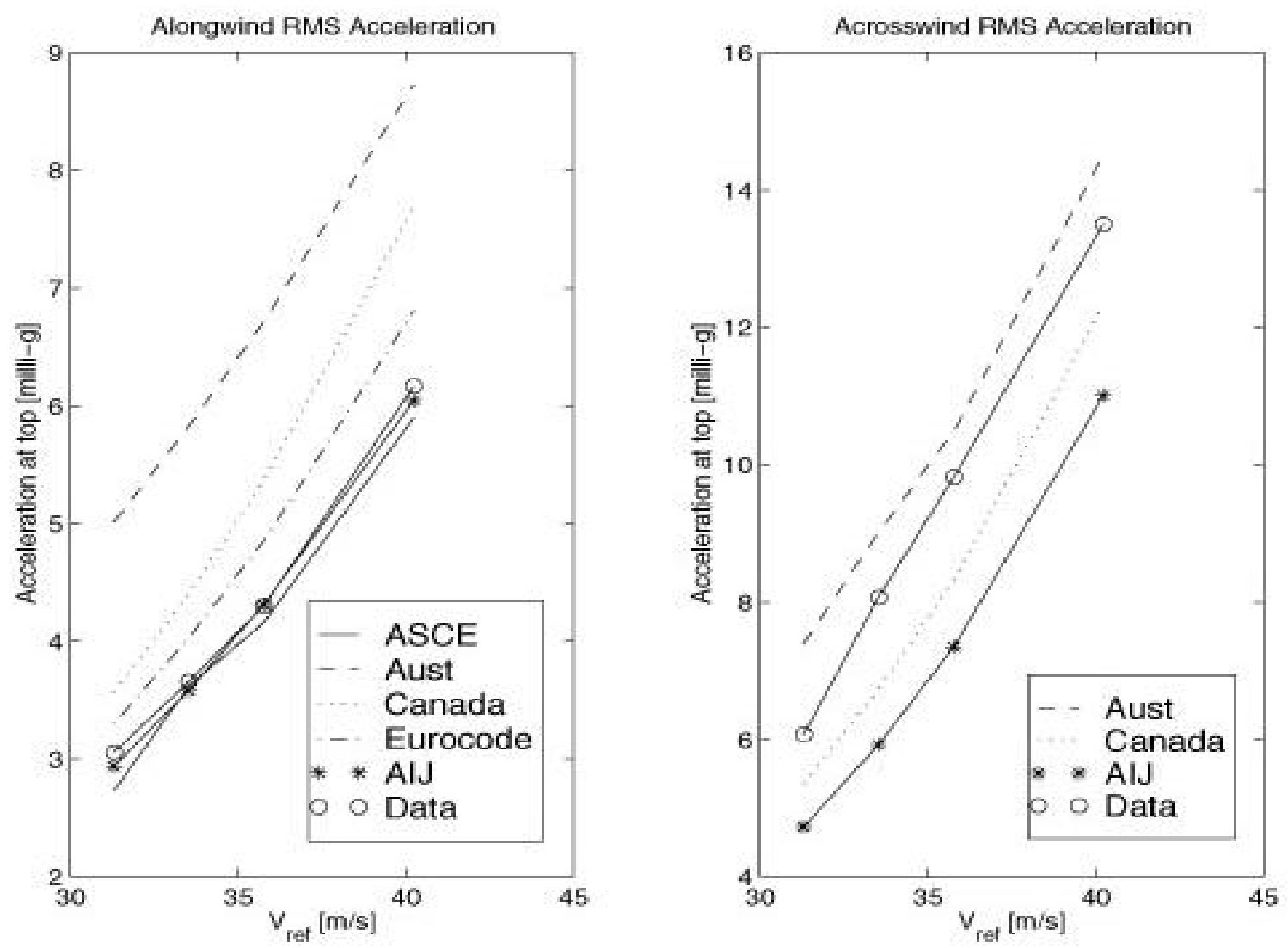

FIGURE 9. Comparison of alongwind and acrosswind RMS accelerations from international standards with wind tunnel data.

\subsection{Acrosswind Response}

For the acrosswind direction, most of the standards conservatively estimate the RMS acceleration, as also shown by Fig. 9. Still, of the codes which provide some estimate, the Australian Standard best matches the test data without underestimating the RMS acceleration (Table 4). It is important to note that while 
the AIJ estimates lie below all others shown here, the empirical expression typically falls within $30 \%$ of the measured values, according to the standard.

TABLE 4. Comparison of Calculated Peak and RMS Acrosswind Accelerations from International Codes \& Standards with Wind Tunnel Data.

\begin{tabular}{|c|c|c|c|c|c|}
\hline & $\begin{array}{c}\text { Ref } \\
\text { Velocity } \\
{[\text { mph] }}\end{array}$ & Australia & Canada & AIJ & Data \\
\hline \multirow{4}{*}{$\begin{array}{l}\text { Acrosswind } \\
\text { Peak } \\
\text { Acceleration } \\
\text { [milli-g's] }\end{array}$} & 90 & 52.63 & 46.32 & $38.53^{* *}$ & $47.25^{* *}$ \\
\hline & 80 & 38.04 & 31.24 & $25.72^{* *}$ & $34.37^{* *}$ \\
\hline & 75 & 32.70 & 25.19 & $20.72^{* *}$ & $28.24^{* *}$ \\
\hline & 70 & 26.82 & 20.03 & $16.55^{* *}$ & $21.24^{* *}$ \\
\hline \multirow{4}{*}{$\begin{array}{l}\text { Acrosswind } \\
\text { RMS } \\
\text { Acceleration } \\
\text { [milli-g's] }\end{array}$} & 90 & $14.51 *$ & $12.32 *$ & 11.01 & 13.50 \\
\hline & 80 & $10.49 *$ & $8.33^{*}$ & 7.35 & 9.82 \\
\hline & 75 & $9.02 *$ & $6.73 *$ & 5.92 & 8.07 \\
\hline & 70 & $7.39 *$ & $5.36^{*}$ & 4.73 & 6.07 \\
\hline
\end{tabular}

\subsection{Torsional Response}

In addition, a comparison of the torsional-induced lateral RMS acceleration at the building corner, as predicted by the AIJ standard and the wind tunnel data, was conducted. Eq. (89) has been used in this study to adjust for the mode shapes of the measured torsional spectrum. As a further exercise, the accelerations computed by the empirical expression developed at UWO are also presented. As shown in Fig. 10 and Table 5, the UWO empirical equation gives conservative estimates for the response of this model building in comparison to the wind tunnel data, while the AIJ estimates are greater than the wind tunnel estimates, with especially at higher wind speeds. However, AIJ 1996 Recommendations states that the comparison with full scale measurements has confirmed that measured responses are typically smaller than the estimate in the standard by less than $30 \%$, which may explain its discrepancy with the wind tunnel data. 


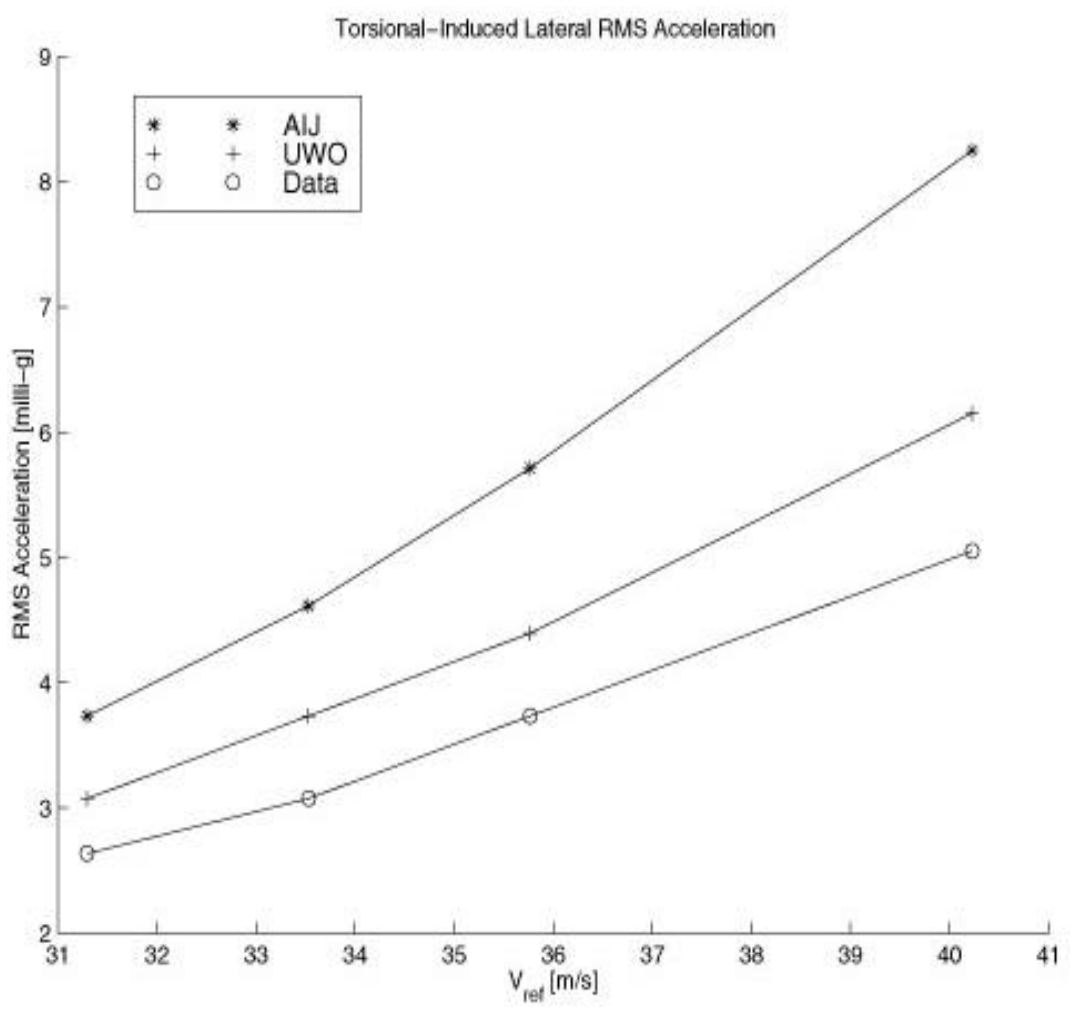

FIGURE 10. Comparison of torsional-induced lateral acceleration at corner of building with wind tunnel data.

TABLE 5. Comparison of Calculated Torsional-Induced Lateral Accelerations at Corner of Building with Wind Tunnel Data.

\begin{tabular}{||l||c|c||c||c|}
\hline \hline & $\begin{array}{c}\text { Ref } \\
\text { Velocity } \\
\text { [mph] }\end{array}$ & AIJ & $\begin{array}{c}\text { Wind } \\
\text { Tunnel } \\
\text { Data }\end{array}$ & $\begin{array}{c}\text { UWo } \\
\text { Equation }\end{array}$ \\
\hline $\begin{array}{l}\text { Torsional- } \\
\text { Induced Lateral } \\
\text { RMS }\end{array}$ & 90 & 8.25 & 5.05 & 6.15 \\
$\begin{array}{l}\text { Acceleration } \\
\text { [milli-g's] }\end{array}$ & 70 & 5.71 & 3.73 & 4.39 \\
\hline
\end{tabular}

\subsection{Conclusion}

The use of the gust factor approach in international standards makes it fairly simple to evaluate the response of a structure due to both its mean and fluctuating components, with each standard applying the gust factor approach uniquely. The validity of the assumptions and applications of this widely-accepted theory, and its applications in international codes and standards, has been explored, in light of wind tunnel data. This study not only validates wind tunnel-based empirical expressions for the acrosswind and torsional responses, but also provides an additional data base of wind tunnel results for buildings of vari- 
ous aspect ratio and shape, tested in simulated urban and suburban terrain. This data base will soon be available on the internet for use. From the analyses conducted in this study, the following may be concluded:

(1) As expected, the gust factors reflect the differences in gust duration which each standards applies.

(2) The AIJ and ASCE7-95 estimates closely match the alongwind measured RMS acceleration for the model building tested in a wind tunnel.

(3) Of the standards providing procedures to estimate the acrosswind RMS acceleration, the Australian Standard was closest to the wind tunnel data, while noting that the bounds specified for the estimates in the AIJ standard also place it within the range of the wind tunnel findings.

(4) The torsional-induced lateral acceleration approximated by AIJ Recommendations, the UWO's empirical relationship, and the wind tunnel data are all quite close, further validating the effectiveness of wind tunnel-based empirical expressions for the torsional response.

\subsection{Acknowledgments}

The support for this work was provided in part by NSF Grant No. CMS-9503779. The authors are thankful to Dr. Po Chen Lu, presently at Tamkung University, Taiwan, for his assistance in collecting and analyzing the wind tunnel data, Dr. Yukio Tamura, of Tokyo Polytechnic Institute, Japan, for his assistance with the calculations regarding the AIJ standard, and Dr. Dale Perry of Texas A\&M University for his review of the manuscript.

\subsection{References}

AIJ Recommendations for Loads on Buildings (1993), Architectural Institute of Japan, Japan. (in Japanese)

AIJ Recommendations for Loads on Buildings (1996), Architectural Institute of Japan, Japan.

ASCE Standard, ASCE7-95: Minimum Design Loads for Buildings and Other Structures (1995), American Society of Civil Engineers, New York.

Australian Standard: Minimum Design Loads on Structures (known as the SAA Loading Code) Part 2: Wind Loads (1989), Standards Australia, Sydney.

Boggs, D.W. and Peterka, J.A. (1989), “Aerodynamic Model Tests of Tall Buildings,” J. of Eng. Mech., ASCE, 115(3) 618-635.

British Standard, Loadings for Buildings - Part 2: Code of Practice for Wind Loads (1995), Building and Civil Engineering Sector Board, United Kingdom.

China National Standard: GBJ9 Load Code for Building Structures (1987), China. 
Chiu, G.L.F. and Perry, D.C. (1997), "Low-Rise Building Wind Load Provisions - Where Are We and Where Do We Need to Go," Eng. J., AISC 4th quarter.

CWE-92: Computational Wind Engineering I (1993), editor, S. Murakami, Elsevier Science B.V.

CWE-96: Computational Wind Engineering II (1997), editor, R.N. Meroney and B. Bienkiewicz, Elsevier Science B.V.

Davenport, A.G. (1967), “Gust Loading Factors,” J. of Str. Div., ASCE 93(ST3) 11-34.

ESDU (1989), "Calculation Methods for Along-Wind Loading. Part 3: Response of Buildings and PlateLike Structures to Atmospheric Turbulence," Item No. 88019, with amendments A\&B, ESDU International, London, March.

European Prestandard, Ratified European Text, Eurocode 1: Basis of Design and actions on structures Part 2-4: Actions on Structures - Wind Actions (1995), European Committee for Standardization.

Ferraro, V., Irwin, P.A., and Stone, G.K. (1989), "Wind Induced Building Accelerations," Proc. of the 6th US Natl. Conf. on Wind Eng., Houston, Texas.

Greig, G.L. (1980), “Toward an Estimate of Wind-Induced Dynamic Torque on Tall Buildings,” Master's Thesis, Department of Engineering, University of Western Ontario, London, Ontario.

Gurley, K. and Kareem, A. (1993), "Gust Loading Factors for Tension Leg Platforms," App. Ocean Research 15(3) 137-154.

Holmes, J.D., Melbourne, W.H., and Walker, G.R., (1990), A Commentary on the Australian Standard For Wind Loads, Australian Wind Engineering Society, Australia.

Kareem, A. (1982), “Acrosswind Response of Buildings,” J. of Struct. Eng., ASCE, 108(ST4) 869-887.

Kareem, A. (1984), "Model for Prediction of the Acrosswind Response of Buildings," Eng. Struct., 6(2) 136-141.

Kareem, A. (1985), "Lateral-Torsional Motion of Tall Buildings to Wind Loads," J. of Struct. Eng., ASCE, 111(11) 2749-2496.

Kareem, A. (1987), "Wind Effects on Structures: A Probabilistic Viewpoint," Probabilistic Eng. Mech., 2(4) 166-200.

Kareem, A. (1989), "Mapping and Synthesis of Random Pressure Fields," J. of Eng. Mech., ASCE, 115(10).

Kareem, A. (1990), "Measurements of Pressure and Force Fields on Building Models in Simulated Atmospheric Flows," J. of Wind Eng. and Ind. Aero. 36 589-599.

Kareem, A. (1992), “Dynamic Response of High-Rise Buildings to Stochastic Wind Loads,” J. of Wind 
Eng. and Ind. Aero. 41-44 1101-1112.

Kareem, A. and Cermak, J.E. (1979), "Wind Tunnel Simulation of Wind-Structure Interactions," ISA Transactions, 18(4) 23-41.

Kareem, A., Tognarelli, M., and Gurley, K. (1997), "Modeling and Analysis of Quadratic Term in the Wind Effects on Structures," Proc. of the 2nd European Conf. on Wind Eng., Genova, Italy, June.

Katagiri, J. et al (1992), "Wind-Induced Lateral Torsional Motion of a Tall Building," J. of Wind Eng. and Ind. Aero., 41 1127-1137.

Lee, B.E. and Ng, W.K. (1988), "Comparisons of Estimated Dynamic Along-Wind Responses," J. of Wind Eng. and Ind. Aero., 30 153-162.

Loh, P. and Isyumov, N. (1985), "Overall Wind Loads on Tall Buildings and Comparisons with Code Values," Proc. of the 5th US Natl. Conf. on Wind Eng., Lubbock, Texas.

National Building Code of Canada (1995), Canadian Commission on Building and Fire Codes, National Research Council, Canada.

Reinhold, T.A., and Kareem, A. (1986), "Wind Loads and Building Response Predictions Using Force Balance Techniques," Proc. of the 3rd ASCE Eng. Mech. Conf. - Dynamics of Structures, UCLA.

Simiu, E. (1976), "Equivalent Static Wind Loads for Tall Building Design," J. of Struct. Div., ASCE, 102(4) 719-737.

Simiu, E. and Scanlan, R. (1996). Wind Effects on Structures: Fundamentals and Applications to Design, 3rd Ed., Wiley \& Sons, Inc., New York.

Simiu, E. and Stathopoulos, T. (1997), "Codification of Wind Loads on Buildings Using Bluff Body Aerodynamics and Climatological Data Bases," J. of Wind Eng. and Ind. Aero. 69-71 497-506.

Solari, G. (1982), “Alongwind Response Estimations. Closed Form Solution,” J. of Struct. Div., ASCE, 108(1) 225-244.

Solari, G. and Kareem, A. (1997), "On the Formulation of ASCE7-95 Gust Factor," Proc. of the 8th US Natl. Conf. on Wind Eng., CD ROM, Johns Hopkins University, Baltimore, June (also to appear in J. of Wind Eng. and Ind. Aero.).

Tamura, Y., T. Ohkuma, and Kanda, J. (1996). Wind Resistant Design, Kajima Corp, Japan (in Japanese).

Tschanz, T. and Davenport, A.G. (1983), "The Base Balance Technique for the Determination of Dynamic WInd Loads," J. of Wind Eng. and Ind. Aero., 13(1-3) 429-439.

Vellozzi, J. and Cohen, H. (1968), “Gust Response Factors,” J. Struct. Div., ASCE, 97(6) 1295-1313.

Vickery, B.J. (1970), “On the Reliability of Gust Loading Factors," Proc. of Technical Mtg.: Wind 
Loads, NBS, Washington, D.C.

Vickery, P.J., et al (1985), "The Effect of Modal Shape on the Wind-Induced Response of Tall Buildings," Proc. of the 5th US Natl. Conf. on Wind Eng., Lubbock, Texas. 
Keywords: Gust Factor, Dynamic Wind Effects, Design Codes and Standards, Alongwind Response, Acrosswind Response, Torsional Response, Turbulence, Reliability. 